\title{
A multicomponent approach to using waste-derived biochar in biofiltration : A case study based on dissimilar types of waste
}

\section{Baltrenaite, Edita}

2017-04

Baltrenaite , E , Baltrenas , P , Bhatnagar , A , Vilppo , T, Selenius , M , Koistinen , A , Dahl , M \& Penttinen , O-P 2017 , ' A multicomponent approach to using waste-derived biochar in biofiltration : A case study based on dissimilar types of waste ' , International Biodeterioration and Biodegradation , vol. 119 , pp. 565-576 . https://doi.org/10.1016/j.ibiod.2016.10.056

http://hdl.handle.net/10138/311372

https://doi.org/10.1016/j.ibiod.2016.10.056

cc_by_nc_nd

acceptedVersion

Downloaded from Helda, University of Helsinki institutional repository.

This is an electronic reprint of the original article.

This reprint may differ from the original in pagination and typographic detail.

Please cite the original version. 


\title{
A SYSTEMATIC APPROACH TO USING WASTE-DERIVED BIOCHAR IN BIOFILTRATION: A CASE STUDY BASED ON DISSIMILAR TYPES OF WASTE
}

\author{
Edita Baltrènaitè1, , Pranas Baltrènas², Amit Bhatnagar3, Teemu Vilppo4, Olli-Pekka Penttinen5, Mari \\ Dahl 6 \\ 1,2Vilnius Gediminas Technical University, Saulètekio al. 11, Vilnius-40, Lithuania \\ 3,4Department of Environmental Sciences, University of Eastern Finland, Yliopistonranta 1E, Kuopio, \\ Finland \\ 5,6Department of Environmental Sciences, Helsinki University, Niemenkatu 73, 15140 Lahti, Finland \\ *Corresponding author: baltrenaite@aol.com
}

\begin{abstract}
The environmental legislation and strict enforcement of environmental regulations are the tools effectively used for developing the market of materials for environmental protection technologies. Sustainability criteria shift environmental engineering systems to more sustainable-material-based technologies. For carbon-based medium materials in biofiltration, this trend results in attempts to use biochar for biofiltration purposes. The paper presents the analysis of biochar properties based on the main criteria for biofiltration medium integrating the environmental quality properties of biochar, following the European Biochar Certificate guidelines. Three types of biochar produced from feedstock of highly popular and abundant types of waste are analysed. A systematic approach was applied to summarize the results. The lignocellulosic type of biochar was found to be more competitive for use as a biofiltration medium than the types of biochar with high ash or lignin content.
\end{abstract}

Keywords: biochar, biofiltration, woodchips, lignin, sludge

\section{Introduction}

The widely-discussed general benefit of biochar used as soil amendment to climate change mitigation is formed of various biochar benefits to soil, including provision of soil biota functional redundancy, the increase in soil organic carbon stability, reduction of $\mathrm{N}_{2} \mathrm{O}$ emissions, facilitation of soil formation, favoring hydrological cycle and soil water to plants, modification of the rhizosphere microbiome and the support of the soil pH buffering capacity (Tammeorg et al. 2016). The deeper knowledge of biochar's role in soil helps us to study its use for soil remediation and in contact with contaminants (Hilber et al. 2016) or to investigate biochar effect on a field scale (Verheijen et al. 2016). With high diversity of biochar properties, the need for classifying biochar not only for a particular soil type, but also for more specific biochar application niches, becomes urgent (Mayer et al. 2016). This is especially practical, when biochar is applied to particular environmental technologies, requiring high efficiency, as well as providing the environmental, practical and economical benefits.

Biofiltration is among the sustainable environmental technologies, which are widely used for reducing volatile compounds released by industrial processes, and, therefore, contribute to the reduction of air pollution, which is classified as one of major contributors to world population health impacts (WHO 2016). Biofiltration uses microorganisms fixed to a porous medium to break down the pollutants present in an air stream and, typically, incorporates some form of water addition to control moisture content and to add nutrients.

The benefits of biofilters over other air treatment technologies are as follows: they are highly efficient at removing volatile compounds from the air, the products of the reactions taking place in the device are not dangerous, and most of pollutants can be removed. Besides, they have a simple structure, use locally available materials as biofiltration media, have a considerably long service life (10 years), require a relatively small capital, low operating costs and energy requirements, as well as being highly reliable and easy to maintain and service. Their disadvantages include a large space occupied by the equipment, as well as more complicated moisture and $\mathrm{pH}$ control within the process (Baltrènaite et al. 2016). 
1 The overall effectiveness of a biofilter is largely governed by the properties and characteristics of the 2 support medium, including porosity, a degree of compaction, water retention capabilities and the 3 ability to host microbial communities. The criteria, describing the ability of a material to facilitate the 4 effective treatment of the biofiltration system, are given in Figure 1.

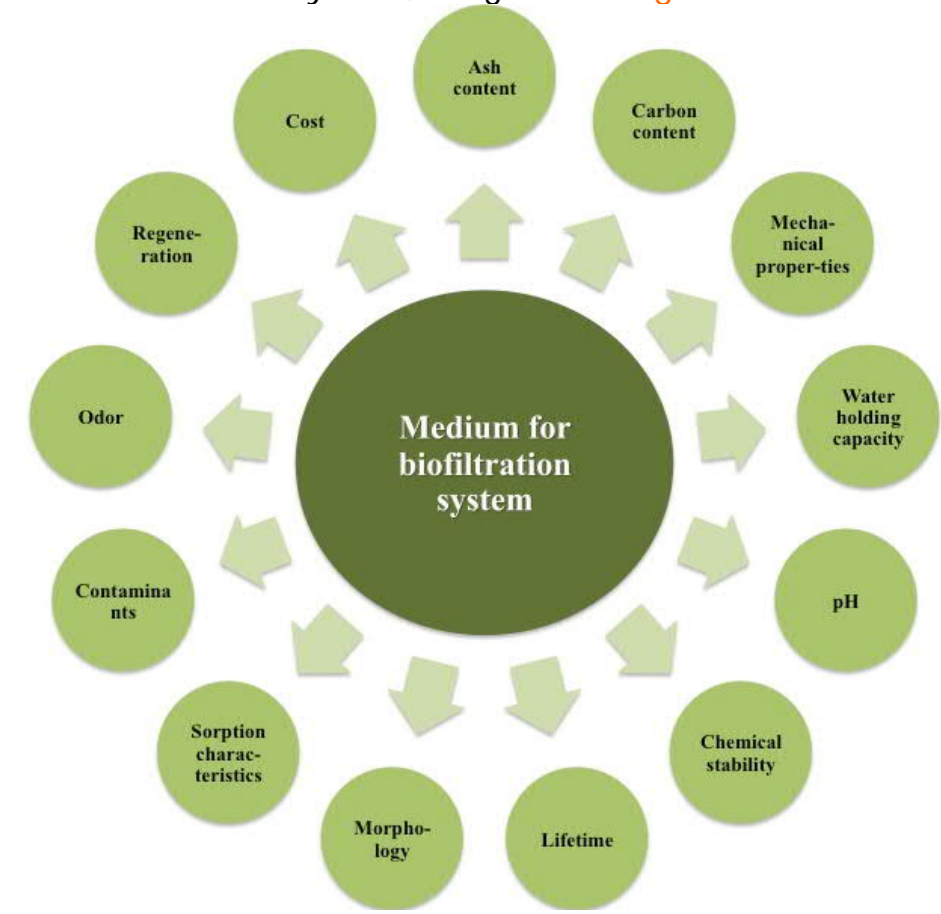

Fig 1. The criteria for selecting the medium for use in the biofiltration system

The activated carbon has been a historically common medium in the biofiltration systems. However, biochar also has some advantages. In particular, it has a relatively low cost due to local availability and is easily prepared (e.g., avoiding the activation of the adsorbent). It also has a high potential of regeneration because of the prevalence of physical adsorption, a low probability that the adsorbent will cause chemical reactions, the convenient filling of large-volume biofiltration systems, thermal and chemical stability, durability and a possibility of producing an adsorbent from biodegradable waste (Baltrènas et al. 2016).

The abundance and diversity of waste materials as possible feedstock for biochar production implies that a more on-depth discussion about biochar properties in relation to biochar use in biofiltration systems is required. Therefore, the aim of this study is to investigate the applicability of biochar produced from three dissimilar types of biodegradable waste at two principal temperatures for the use as biofiltration media. The systematic approach was used to integrate various biochar properties.

\section{Materials and methods}

\subsection{Selection of feedstock and biochar production}

Biochar was produced from three dissimilar types of feedstock: woodchips, lignin and sewage sludge. Sewage sludge (S) was collected from an urban WWTP in Klaipèda, the third largest city in Lithuania, with a population of about 159 thousand people in 2013. Sewage sludge production in the Klaipedda region has been calculated as 47 thousand tonnes per year (Havukainen et al. 2011). Sewage sludge was subjected to digestion, dewatering and low-temperature drying treatment. Woodchips (C) were provided by a sawmill in Kaliningrad, Russian Federation. In 2006, 21\% (362 thousand tonnes) of the total wood waste imported to the EU came from Russia (Villanueva et al. 2010). Lignin (L) was obtained as a by-product of a sugar refining industry based in Lithuania. These materials were chosen for biochar production because of their wide availability. Pyrolytic treatment considered in this paper 
could be a good waste management option for these types of feedstock obtained in high amounts (e.g. sludge, woodchips) or has a high potential for a good biochar product due to high content of lignin (e.g. lignin). Biochar use for biofiltration could present even higher diversification of biochar applicability and develop its cascading functionality.

Feedstock was pyrolysed at the temperatures of 450 and $700^{\circ} \mathrm{C}$ for two hours (Mancinelli et al submitted). The sample weight was 50 grams, and the sample was wrapped in the aluminum foil to gain oxygen depletion during the pyrolysis (Kaal et al. 2012). After the pyrolysis, the yield of biochar was determined. Prior to all analyses, the samples of biochar and feedstock were milled manually to homogenize them.

2.2. Bulk density, moisture content, water holding capacity and ash content

Bulk density was measured by weighing $10 \mathrm{ml}$ of a sample according to EBC guidelines (EBC 2012) (analogue VDLUFA-Method A 13.2.1). Moisture content (raw moisture) was analysed according to EBC guidelines (DIN 51718): the samples ( $1 \mathrm{~g}$ ) were dried in the oven at $40^{\circ} \mathrm{Cuntil}$ mass was constant. Water holding capacity (WHC) was determined according to EBC guidelines (DIN ISO 14238-2011) by soaking 5-10 grams of biochar and feedstock in water for $24 \mathrm{~h}$ and then placing biochar on a sandbed for 2 hours to remove excess water. Then, the saturated samples were weighed, dried at $40^{\circ} \mathrm{C}$ and then weighed again. Ash content was determined according to EBC guidelines (DIN 51719). The samples were incinerated in the oven at $550^{\circ} \mathrm{C}$ for an hour. All the samples, except for the case of moisture content determination, were measured in duplicates.

\subsection{The $\mathrm{pH}$ and electrical conductivity}

The pH was measured according to the EBC guidelines (DIN ISO 10390). The sample was rotated together with $0.01 \mathrm{MCaCl}_{2}$ solution (1/ $\left.5 \mathrm{v} / \mathrm{v}\right)$ and the $\mathrm{pH}$ was measured directly from that suspension, using the pH meter Mettler Toledo Seven Multi. Electrical conductivity was analysed according to the EBC guidelines (DIN ISO 11265). The sample in the quantity of 10 grams was shaken with $100 \mathrm{ml}$ of distilled water for one hour. The samples were filtered through the filter paper (VWR 413, particle retention 5/13um, European Cat. No. 516-0817) and analysed using the InoLab WTW series 740 electrical conductivity meter. All samples were measured in duplicates.

2.4. The total carbon (TC), dissolved organic carbon (DOC) and dissolved organic nitrogen (DON) analysis

For TC analysis, the homogenized sample in the quantity of $25 \mathrm{mg}$ was weighted by the Kern 770 scale. TC was measured using the untreated dry samples. The samples were measured using the Shimadzu SSM-5000A TOC-V carbon analyser. For DOC and DON measurements, the sample of $2.5 \mathrm{~g}$ was mixed with $25 \mathrm{ml} 0.5 \mathrm{M}_{\text {of }} \mathrm{K}_{2} \mathrm{SO}_{4}$ and rotated for 1 hour. The solution was diluted with $20 \mathrm{ml}$ of distilled water to obtain a sufficient amount ofleachate for analysis. The solution was filtered through

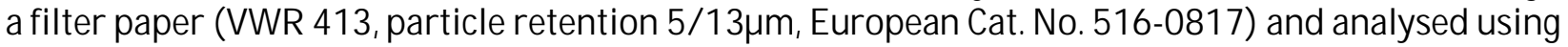
the Shimadzu TOC-V 5000A sampler. The samples, which were not measured the same day, were stored in the fridge (Jones \& Willet, 2006). All samples were measured in duplicates.

\subsection{Elemental composition}

The components $(\mathrm{C}, \mathrm{H}, \mathrm{N})$ of elemental composition were determined using CHN2400 (PerkinElmer, 1997) equipment via the combustion at $950^{\circ} \mathrm{C}$. Prior to the analysis, the samples were carefully ground for homogenization. The total oxygen content was determined by Eq (Novak et al. 2009):

$$
\mathrm{C}_{\mathrm{O}}=100-\left(\mathrm{C}_{\mathrm{a}}+\mathrm{C}_{\mathrm{C}}+\mathrm{C}_{\mathrm{H}}+\mathrm{C}_{\mathrm{N}}\right) \text {, }
$$

where $\mathrm{C}_{0}, \mathrm{C}_{\mathrm{A}}, \mathrm{C}_{\mathrm{C}}, \mathrm{C}_{\mathrm{H}}, \mathrm{C}_{\mathrm{N}}$ denote the content of oxygen, ash, carbon, hydrogen and nitrogen, respectively, $\% \mathrm{w} / \mathrm{w}$.

\subsection{FTIR analysis}


Six samples were labelled as C450, C700, L450, L700, S450 and S700 referring to the type of biochar feedstock (C - woodchips, L - lignin and S - sludge), while '450' or '700' indicated the production temperature. For reference, the untreated wood spectra were included. The samples were measured using the Bruker Alpha-P diamond ATR-FTIR spectrometer.

\subsection{SEM images of biochar samples}

The samples were prepared by taking a random portion of biochar on a Petri dish. The particles were fixed on a double-sided carbon type by dipping a SEM stub into biochar. SEM observation was performed using a scanning electron microscope SIGMA HD (Carl Zeiss Ltd, Cambridge, UK). The acceleration voltage $3 \mathrm{kV}$ and secondary electron (SE) imaging were used.

\subsection{PAH analysis}

The internal standard PAH-Mix 31 deuterated (a mixture containing naphthalene D8, acenaphthene D10, phenanthrene D10, chrysene D12 and perylene D12), the recovery standard Anthracene D10 and the calibration standard PAH-Mix 9 deuterated (a mixture containing each of the 16 EPA PAHs) were purchased from Dr. Ehrenstorfer, Augsburg, Germany. Toluene (gas chromatography grade) was obtained from Merck, Darmstadt, Germany, while Soxhlet extraction thimbles were purchased from Whatman, Maidstone, England.

Biochars were homogenized with mortar and a pestle. The dry weight was determined in the oven at $105^{\circ} \mathrm{C}$ for $16 \mathrm{~h}$ and the loss on ignition at $550^{\circ} \mathrm{C}$ for $4 \mathrm{~h}$. One gram of non-dried biochar sample was put into the extraction thimble and covered with cotton wool. Before setting the thimble into the Soxhlet extractor, $400 \mathrm{ng}$ of each internal standard was added. The extractions were run for $32 \mathrm{~h}$ with $80 \mathrm{~mL}$ of $100 \%$ toluene. The extraction was carried out following the optimized method of Hilber et al. (2012) with some modifications. The extracts were concentrated to $\sim 500 \mu l$ by first using a rotary evaporator and then under the nitrogen stream. Finally, the samples were spiked with $100 \mathrm{ng}$ of the recovery standard.

Quantification of PAHs was performed using Shimadzu GC-MS QP2010 Ultra which was equipped with a capillary GC-column ZB-5MS ( $30 \mathrm{~m} \mathrm{x} \mathrm{0,25} \mathrm{mm}$ x 0,25 $\mu \mathrm{m}$ ) from Phenomenex. Helium was used as a carrier gas in a constant flow mode of $1.0 \mathrm{~mL} / \mathrm{min}$. The injection volume was $1.0 \mu \mathrm{l}$ and the samples were injected using the split-less technique. The injection temperature was $280^{\circ} \mathrm{C}$, ion source temperature was $200^{\circ} \mathrm{C}$ and the interface temperature was $280^{\circ} \mathrm{C}$. The oven temperature was programmed as follows: $1 \mathrm{~min}$ at $80^{\circ} \mathrm{C}$, to $250^{\circ} \mathrm{C}$ at $10^{\circ} \mathrm{C} / \mathrm{min}$, to $280^{\circ} \mathrm{C}$ at $7^{\circ} \mathrm{C} / \mathrm{min}$, to $320^{\circ} \mathrm{C}$ at $20^{\circ} \mathrm{C} / \mathrm{min}$ and $5 \mathrm{~min}$ at $320^{\circ} \mathrm{C}$. The quadruple mass spectrometer was operated in the electron impact ion (EI) mode and the electron energy was $70 \mathrm{eV}$. Quantification was carried out using the internal standard method.

The procedural blank concentrations were analysed for each test in order to estimate the potential contamination. Blank concentrations were determined as the average of two empty thimble runs. The results were not blank corrected. Calibration was performed in the 20-1500 ng/ mL interval by serial dilutions of the PAH-Mix 9. Recoveries were determined by relating the deuterated internal standards added before extraction to the recovery standard added before GC-MS analysis in comparison to the same ratio in the calibration solvents.

\section{Results and discussion}

Suitability of biochar for a biofiltration system was discussed analysing the properties described by the criteria presented in Figure 1. The major attention was given to such properties as ash content, organic (or total carbon) content, mechanical strength (referring to high bulk density), chemical stability (referring to soluble salts or electrical conductivity), dissolved organic carbon and dissolved organic nitrogen), lifetime (referring to aromaticity development), morphology beneficial to microorganisms (referring to pore structure development), sorption characteristics (referring to hydrophilicity level associated with the more hydrophilic nature, when biofiltration is used to treat 
water-soluble compounds and the polarity level referring to biofiltration of polar contaminants) and

\subsection{Ash content}

Ash is the residue, remaining after combustion under specified conditions, which is composed primarily of oxides and sulfates. The ash fraction of biochars is enriched with inorganic noncrystalline (amorphous) and poorly to well-crystallized (mineral) constituents (Kloss et al. 2012). These originate from the feedstock and for the presence of some diluents (e.g. soil, clay minerals) mixed with the feedstock (Singh et al.2010). The inorganic constituents of the ash fraction of biochar are usually metal carbonates, silicates, phosphates, sulfates, chlorides and oxy-hydroxides (Vassilev et al. 2013), some of which contribute to the higher $\mathrm{pH}$.

The presence of ash in the biofiltration material produces an effect on two opposite characteristics of the medium. First, it is associated with a higher bulk density which means a higher mechanical strength. On the other hand, a high-ashed material has a low water holding capacity and, in a biofiltration system, could limit water supply to microorganisms, which degrade contaminants. Therefore, high-ash material should not be used in a biofiltration system.

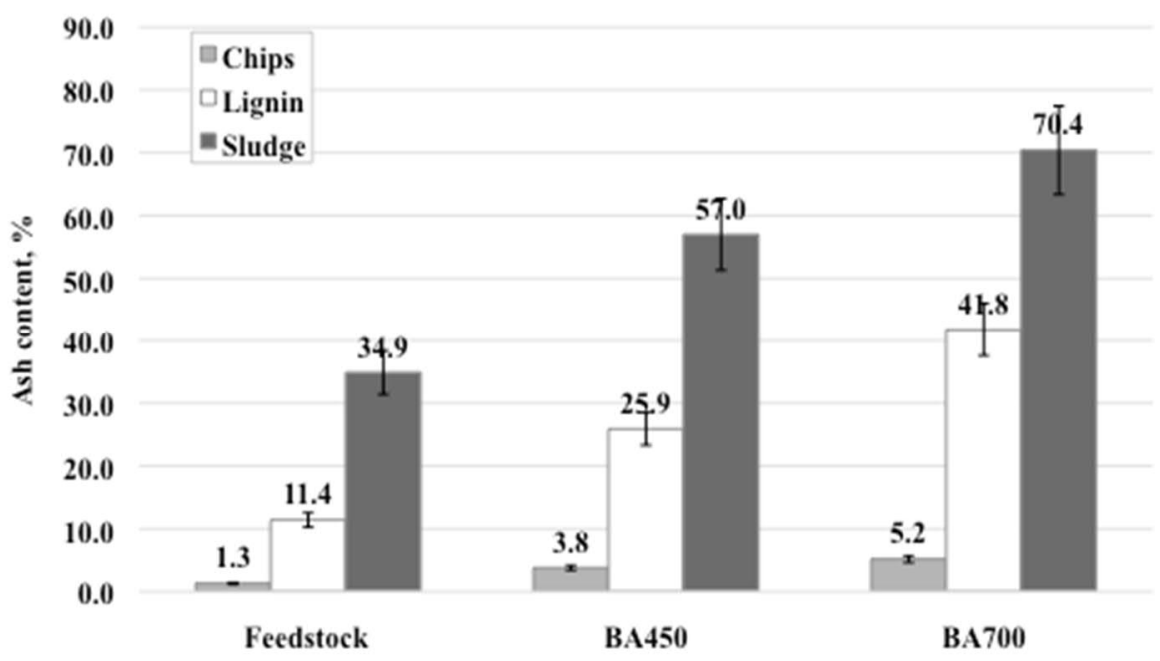

Figure 2. Ash content in three types of feedstock (chips, lignin, sludge) and biochar produced at two temperatures $\left(450^{\circ} \mathrm{C}\right.$ and $\left.700^{\circ} \mathrm{C}\right)$. Error bars denote $\mathrm{SE}(\mathrm{n}=3)$

Ash content of biochar produced at a higher temperature was higher. The trend of ash content to increase in biochar with the increasing temperature was consistent with the data presented in previous studies (Ghani et al. 2013). However, the type of feedstock determined the trends of ash content increase. The highest growth of ash content could be observed in woodchips (by about 3 times higher at the temperature of $450^{\circ} \mathrm{C}$ and about 4 times higher at the temperature of $750^{\circ} \mathrm{C}$. For lignin, ash content increased 2 times at the treatment temperature of $450^{\circ} \mathrm{C}$ and about 3.7 times at the temperature of $750^{\circ} \mathrm{C}$, while for sludge, ash content increased even less (about 1.6 times at the temperature of $450^{\circ} \mathrm{C}$ and about 2 times at the temperature of $750^{\circ} \mathrm{C}$ ).

Biomass-related biochar (woodchips and lignin) had lower ash content compared to mineral type biochar (sludge). The increase in ash content was in the following order: woodchips<lignin<sludge (Fig 2).

\subsection{Total carbon content}


1 The total carbon content in a biofiltering material is important as the extra source of energy, when 2 the contamination load is reduced by the biofiltration systems. This is typical of industries with the 3 varying emission load.

4 Biochar which is rich in ash, usually presents lower total carbon content. This characteristic was also total carbon content and this can be attributed to the fact that lignin is the source of the most of pyrogenic carbonaceous materials (Brown et al. 2015).

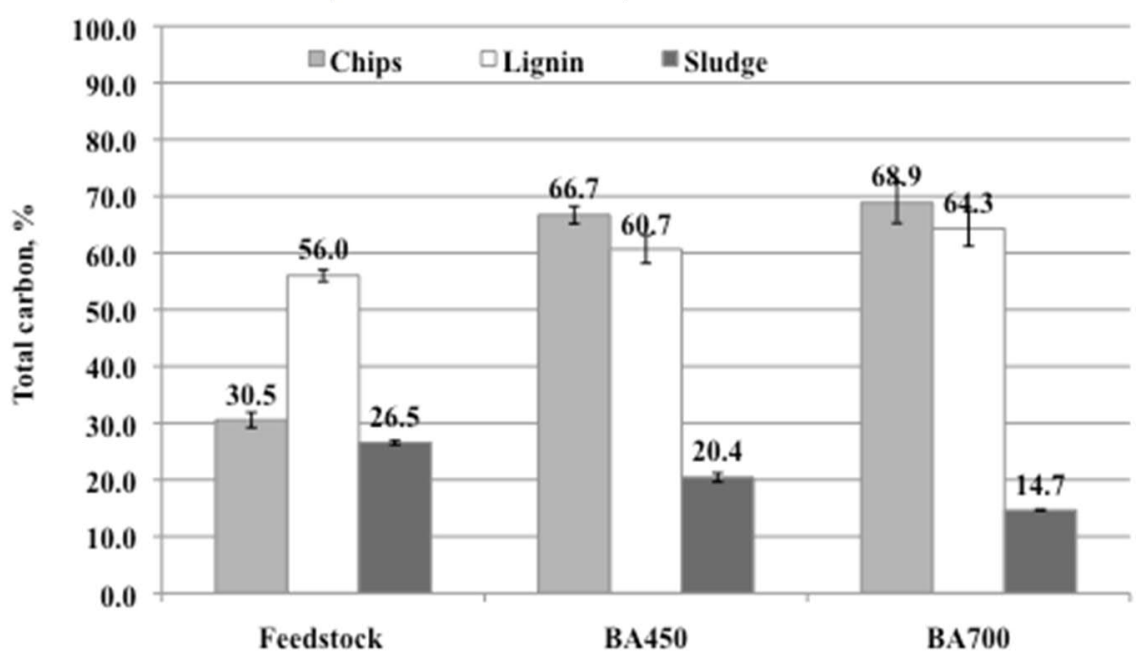

Figure 3. The total carbon content in three types of feedstock (chips, lignin, sludge) and biochar produced at two temperatures $\left(450^{\circ} \mathrm{C}\right.$ and $\left.700^{\circ} \mathrm{C}\right)$. Error bars denote $\mathrm{SE}(\mathrm{n}=3)$

The total carbon content in lignin and woodchips' biochar was over $60 \%$ at both temperatures, but reached only $20 \%$ in sludge biochar at $450{ }^{\circ} \mathrm{C}$ and $15 \%$ in sludge biochar at $700^{\circ} \mathrm{C}$. According to the EBC guidelines, biochar should contain at least 50\% of carbon (EBC 2012). This requirement is not satisfied for the examined sludge biochar. Therefore, the pyrolysis product of sludge should not be classified as biochar but, preferably, just as char or pyrochar. Figure 3 shows that biochar obtained from lignin and woodchips at the temperature of $450-700^{\circ} \mathrm{C}$, can be referred to medium C-containing biochar (with $60-80 \%$ of total carbon), with the potential close to that of organic carbon. Sludge biochar, as well as feedstock of all the studied types, are low C-containing materials $(<60 \%)$. In the study by Spokas et al. (2011), the carbon content in biochar made of woodchips varied from 69 to $87 \%$, while in the study of Keiluweit et al. (2010), the C content in pine-woodchips' biochar was $92 \%$ at $700^{\circ} \mathrm{C}$. TC content was higher in lignin and woodchips at a higher pyrolysis temperature, but lower in sludge biochar (Fig. 3). This was also demonstrated in the study of Enders et al. (2012), where the authors concluded that TC in biochars increased at higher temperatures for low-ash feedstock (lignin and woodchips in this study), but declined in high-ash feedstock (sludge in this study).

\subsection{Bulk density}

As mentioned above, the higher bulk density is associated with higher mechanical strength, which is an important characteristic of the biofiltration system's medium.

The relatively strong linear dependence of bulk density on the ash content observed for all studied types of feedstock and biochar (Fig 4) is in line with the findings of other researchers. Brewer et al. (2009) found that solid density of biochar increased with the increase in ash content and process temperature (Note that solid density is the same as true density and skeletal density, but differs from the bulk density because the latter is calculated, taking into account the voids between biochar particles and, therefore, can be lower than solid density). 


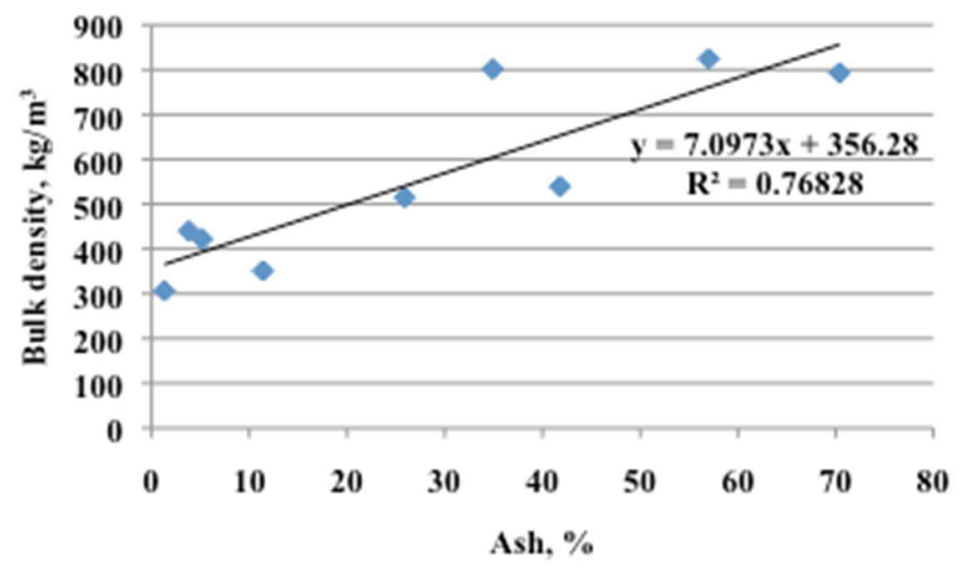

1

Fig 4. The dependence of bulk density on ash content in three types of feedstock (chips, lignin, sludge) and biochar produced at two temperatures $\left(450^{\circ} \mathrm{C}\right.$ and $\left.700^{\circ} \mathrm{C}\right)$

The bulk density is related to the mechanical strength, which is the characteristic used to define the biochar ability to withstand wear and tear during its use. In biofiltration systems, the media should remain stable with time. No clogging or shrinking of the media bed due to material decomposition, bed compaction, or water condensation should occur.

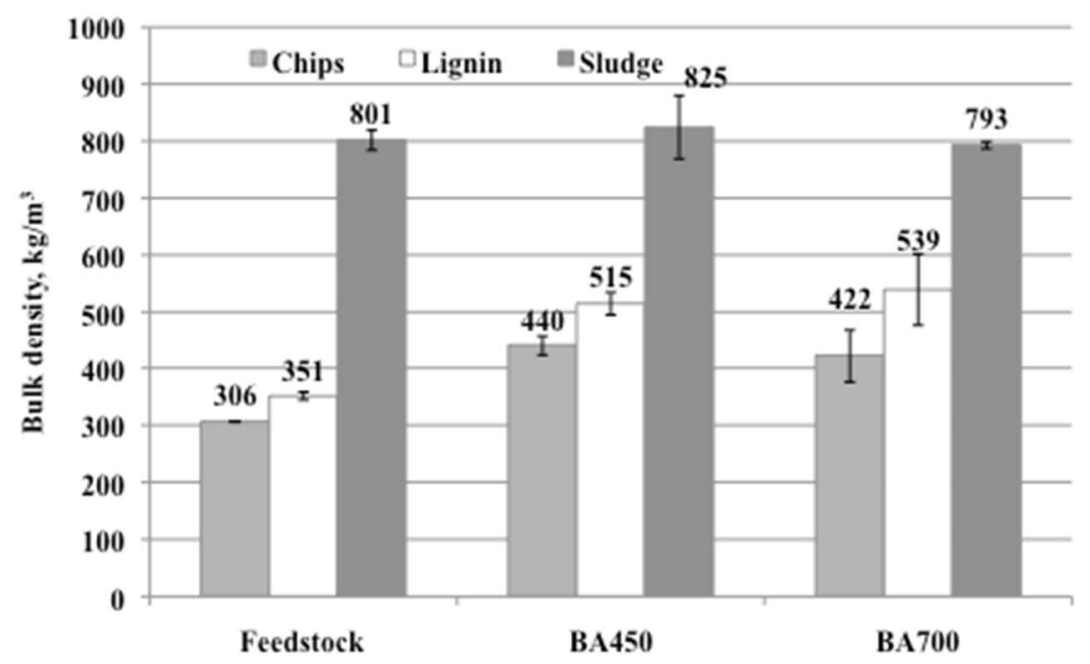

\section{Figure 5. Bulk density of three types of feedstock (chips, lignin, sludge) and biochar produced at two temperatures $\left(450^{\circ} \mathrm{C}\right.$ and $\left.700^{\circ} \mathrm{C}\right)$. Error bars denote $\mathrm{SE}(\mathrm{n}=3)$}

As shown in Fig 5, in testing the materials, a highest bulk density was found for sludge and the lowest was determined for woodchips. The biochar production temperature had a stronger effect on bulk density of woodchips and lignin (their bulk density increased by about 1.5 times) than on sludge (the change was negligible). This implies that higher-ash feedstock is characterized by a higher bulk density and lower water holding capacity, and these properties are similar to those of the biochar derived from this type of feedstock. Higher bulk density and, thus, a lower water holding capacity were determined for the feedstock with higher lignin content (i.e. lignin rather than woodchips). Therefore, the lignin content may also be associated with higher bulk density, but lower water holding capacity. A strong lignin effect on higher bulk density of biochar was also observed by Aygun et al. (2003). 
1 According to the bulk density of the material, the depth of its use in the biofilter will be limited. For 2 example, the materials with the bulk density ranging from 300 to $500 \mathrm{~kg} / \mathrm{m}^{3}$ are easily compacted 3 and, therefore, should be used in the layers up to 1-1.5 $\mathrm{m}$ deep, whereas the materials with the bulk 4 density of 1000-1500 kg/ m³ , could be used for layers as deep as $5 \mathrm{~m}$ (Devinny et al. 1999). Sludge 5 and its biochar had higher bulk density than biomass and biochar derived from it, but it should be 6 noted that bulk density was measured from the milled samples and, therefore, the macropore 7 structure of biochars was diminished. Therefore, bulk density for non-milled biochars could be higher 8 than that for milled biochars.

9 Although all the studied feedstock was obtained in the form of the particles of about 5-10 mm, other 10 particles could hardly be available for lignin and sludge feedstock, except for wood. Therefore, it 11 implies that only the bulk density of woodchips could be higher if their use in the biofiltration systems 12 is considered.

13

\subsection{Water holding capacity}

Water content in a biofilter is, probably, the most important parameter. The neglect of water content or difficulties in controlling it are the most common causes of poor biofilter operation. The ability of the biofilter medium to hold water benefits stabilization of water content in a biofiltration system. Figure 6 shows that water holding capacity (WHC) increases with the decrease of the bulk density. Lower bulk density is associated with a higher pore volume. The materials with a higher pore volume can store more water, therefore, the materials with lower bulk density (and a higher pore volume) exhibit higher values of WHC.

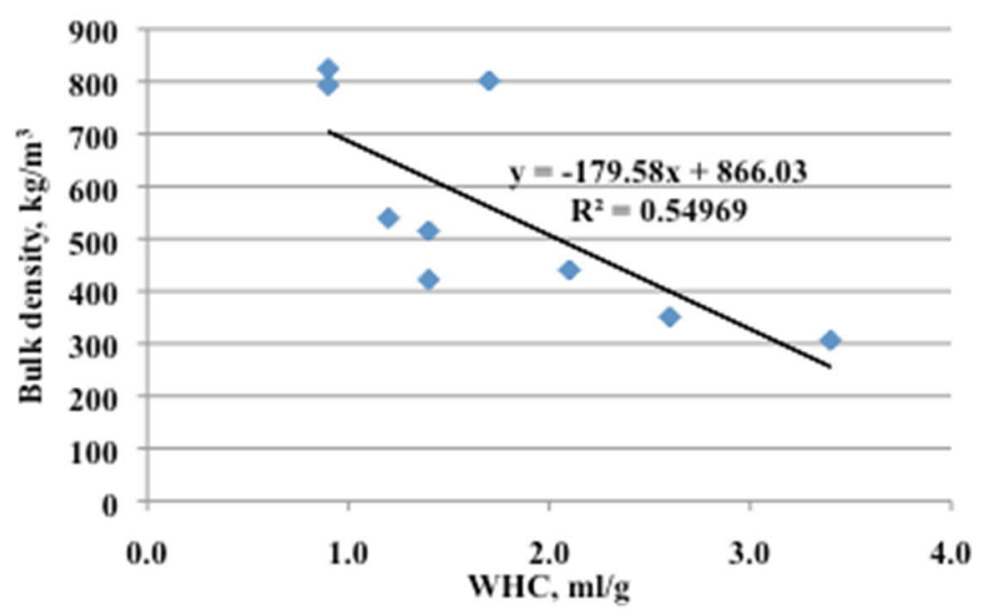

Figure 6. The dependence of water holding capacity on the bulk density of three types of feedstock (chips, lignin and sludge) and biochar produced at two temperatures $\left(450^{\circ} \mathrm{C}\right.$ and $700^{\circ} \mathrm{C}$ ) 


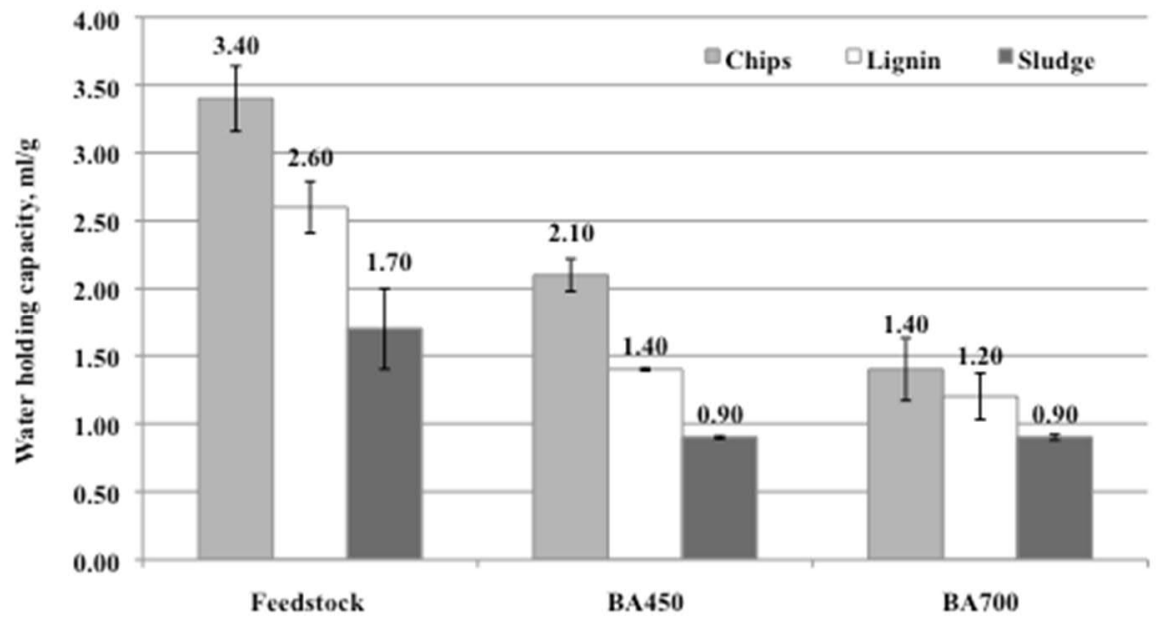

Figure 7. The mean of water holding capacity $(\mathrm{ml} / \mathrm{g})$ in three types of feedstock (chips, lignin and sludge) and biochar produced at two temperatures $\left(450^{\circ} \mathrm{C}\right.$ and $\left.700^{\circ} \mathrm{C}\right)$. Error bars indicate $\mathrm{SE}(\mathrm{n}=3)$

The medium in the biofiltration systems should have the characteristics that favour the operators in keeping the water content at the levels, which nurture the microorganisms. This refers to the WHC. In our study, WHC was higher for feedstock than for the tested types of biochar. Chips had the highest WHC, while sludge biochar showed the lowest value. The samples with higher ash content (e.g. sludge and sludge-derived biochar) had a lower WHC than the samples with lower ash content (e.g. lignin and lignin-derived biochar). The lower WHC was observed for samples with higher lignin content (e.g. lignin and lignin-derived biochar) (Fig 7). However, the WHC was measured in the milled samples and the macropore structure of biochars was diminished. Therefore, the WHC for milled biochars could differ from that for non-milled biochars. In biochar obtained at the temperature of $450^{\circ} \mathrm{C}$, the WHC $(0.9-2.1 \mathrm{ml} / \mathrm{g})$ was slightly smaller. A similar result was also given in other studies (where about $2.9 \mathrm{ml} / \mathrm{g}$ WHC was found in wood and humus biochar $)$, while at the temperature of $700^{\circ} \mathrm{C}(0.9-1.4$ $\mathrm{ml} / \mathrm{g}) \mathrm{WHC}$ of biochar was close to activated biochar WHC $(1.5 \mathrm{ml} / \mathrm{g})$ as determined by Pietikainen (2000)).

\subsection{The $\mathrm{pH}$}

All species of microorganisms proliferate in biofiltration systems over a certain range of the $\mathrm{pH}$ and are inhibited or killed in the conditions outside this range. Most biofilters are designed for operation in the range of about $\mathrm{pH} 7$.

Figure 8 presents a relatively close positive linear relationship between the $\mathrm{pH}$ and WHC of the three types of feedstock and their biochar produced at two different temperatures. The higher $\mathrm{pH}$ values are found for materials with lower WHC. The lower WHC materials were found to also have a higher bulk density (Fig 6) and the higher bulk density is specific for the high-ash materials (Fig 4). As mentioned above, the inorganic constituents of the ash fraction of biochar are usually metal carbonates, silicates, phosphates, sulfates, chlorides and oxy-hydroxides (Singh et al. 2010), and some of which favor a higher $\mathrm{pH}$. 


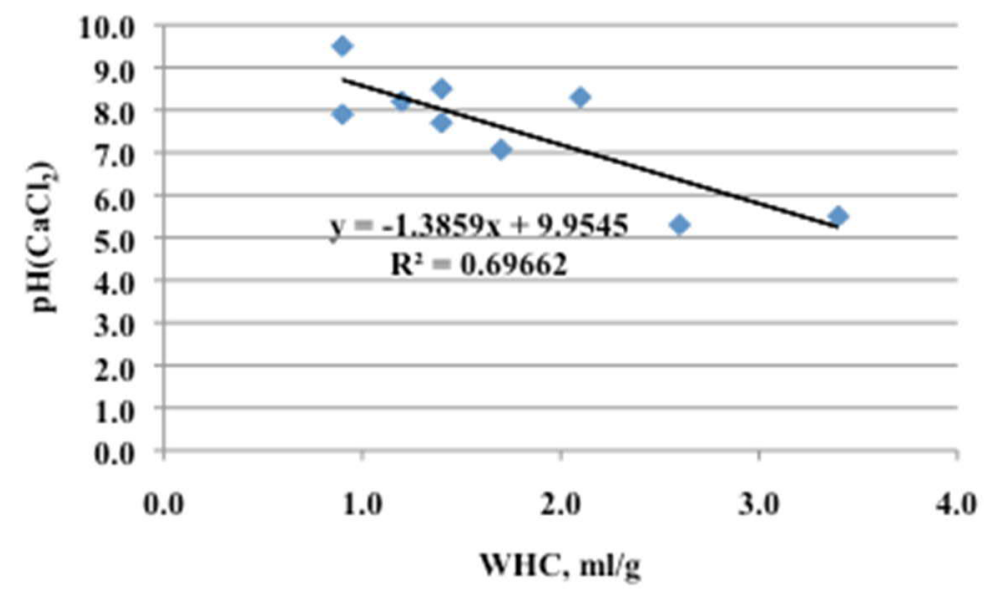

Figure 8. The dependence of water-holding capacity on the $\mathrm{pH}$ of three types of feedstock (chips, lignin and sludge) and biochar produced at two temperatures $\left(450^{\circ} \mathrm{C}\right.$ and $\left.700^{\circ} \mathrm{C}\right)$

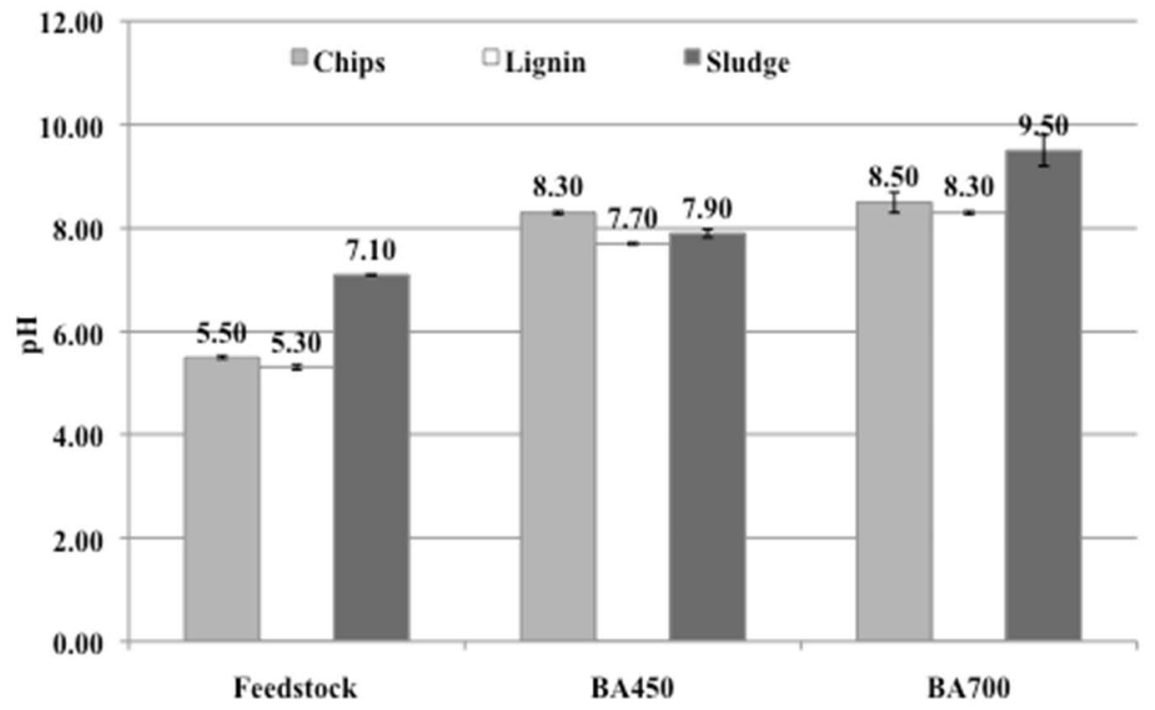

Figure 9. The mean $\mathrm{pH}$ in three types of feedstock (woodchips, lignin, sludge) and biochar produced at two temperatures $\left(450^{\circ} \mathrm{C}\right.$ and $\left.700^{\circ} \mathrm{C}\right)$. Error bars denote $\mathrm{SE}(\mathrm{n}=3)$

The pH values of biochar were higher than the pH of feedstock (Fig 9). The pH was higher in biochar pyrolysed at $700^{\circ} \mathrm{C}$ than that observed at $450^{\circ} \mathrm{C}$. The same trend of increasing the biochar $\mathrm{pH}$ with 10 the increasing temperature has been reported in other studies (Novak et al. 2009, Zhang et al. 2015). 11 The $\mathrm{pH}$ of sludge was higher than the $\mathrm{pH}$ of lignin or woodchips. The highest $\mathrm{pH}$ (9.50) was in sludge12 derived biochar at $700^{\circ} \mathrm{C}$. The trend of the lower $\mathrm{pH}$ was observed in samples with higher lignin 13 content. There is scarce information about the relationship between the $\mathrm{pH}$ and the lignin content in 14 materials. It is believed that the $\mathrm{pH}$ depends on the content of alkaline macroelements, therefore, they, 15 probably, may be treated as lignin impurities. Chupka and Rykova (1983), who studied lignin and its 16 electrical conductivity (depending on the content of $\mathrm{Na}^{+}, \mathrm{Ca}^{+}, \mathrm{Mg}^{2+}, \mathrm{HCO}_{3}{ }^{-}$salts), concluded that 17 electrical conductivity of lignin was intrinsic and not influenced by impurities. This indirectly 18 suggests a low level of impurities in the lignin content and, therefore, a low effect of impurities on 19 lignin properties, such as the $\mathrm{pH}$.

20

21 3.6. Electrical conductivity 
1 Electrical conductivity (EC) allows for indirect measurement of the salt content $\left(\mathrm{Na}^{+}, \mathrm{Ca}^{+}, \mathrm{Mg}^{2+}, \mathrm{HCO}_{3}{ }^{-}\right.$ 2 ) in materials. Soils with high electrical conductivity are characterized by high $\mathrm{pH}$ and are calcium3 rich, which commonly leads to the deficiency of some essential micronutrients (especially, Fe and $\mathrm{Zn}$ ) 4 and macronutrients (especially, phosphorus). In the case of biofiltration, the materials with high 5 electrical conductivity may cause the salts release into the leachate formed when the biofiltration 6 medium is humidified to activate microorganisms.

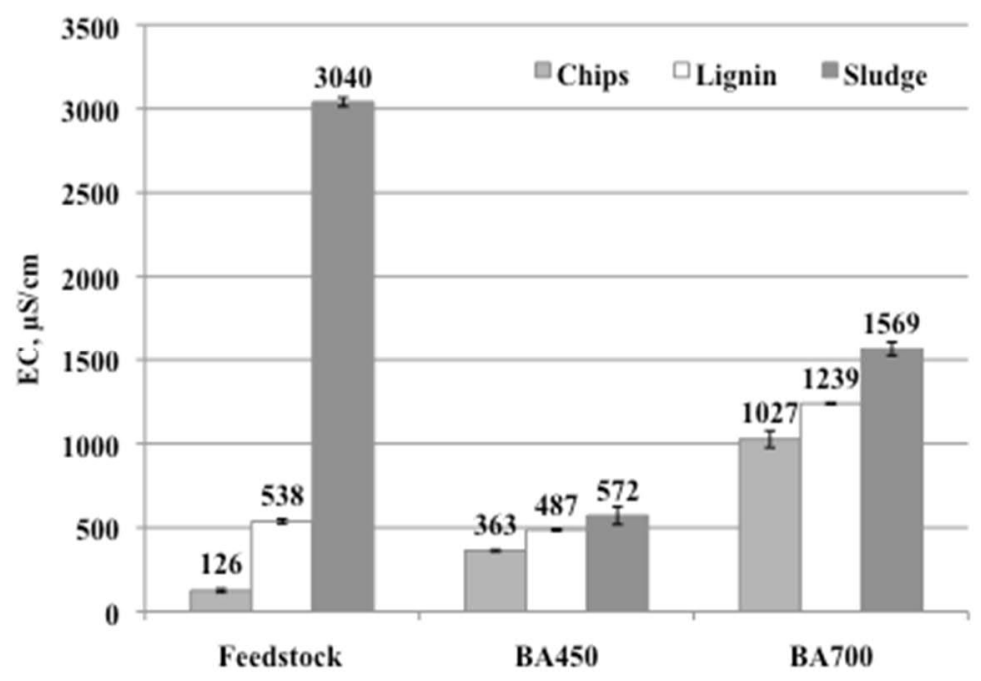

Figure 10. Electrical conductivity of three types of feedstock (chips, lignin and sludge) and biochar produced at two temperatures $\left(450^{\circ} \mathrm{C}\right.$ and $\left.700^{\circ} \mathrm{C}\right)$. Error bars denote $\mathrm{SE}(\mathrm{n}=3)$

The highest electrical conductivity was found in sludge and the lowest in chips. Pyrolysis increased the EC values for lignin and chips, but decreased them for sludge. For all types of biochars, the EC values were higher for biochars treated at $700^{\circ} \mathrm{C}$ than for those treated at $450^{\circ} \mathrm{C}(\mathrm{Fig} 10)$. The EC was higher in the samples with a larger amount of ash (e.g. sludge) and lignin (e.g. lignin).

\subsection{Dissolved organic carbon and dissolved organic nitrogen}

Biochar is both a potential source and sink of dissolved organic matter (DOM). Leaching of DOM that originated from biochar can enhance the loss of the compounds adsorbed by DOM or complexed with DOM (Laird and Rogovska 2015). Organic compounds with a low molecular weight are generated and may be adsorbed on biochar surfaces during pyrolysis. Rostad et al. (2010) have found that the highest concentration of DOM is in biochar of low temperature and rich in aliphatic $\mathrm{C}$.

When applied to soil, biochar can increase the concentration of organic matter and, especially, waterextractable fractions (Lin et al. 2012), while when used as a biofiltration medium, it can increase the amount of water-extractable fractions of carbon and nitrogen (DOC and DON), which are associated with higher or lower stability of the medium, the amount of labile carbon and nitrogen and their effect on the leachate composition. Since several metals (e.g. Cu) form complexes with organic matter (Zimmermann et al. 2011), the materials with high DOC and DON levels should be limited for use as biofiltration media. 


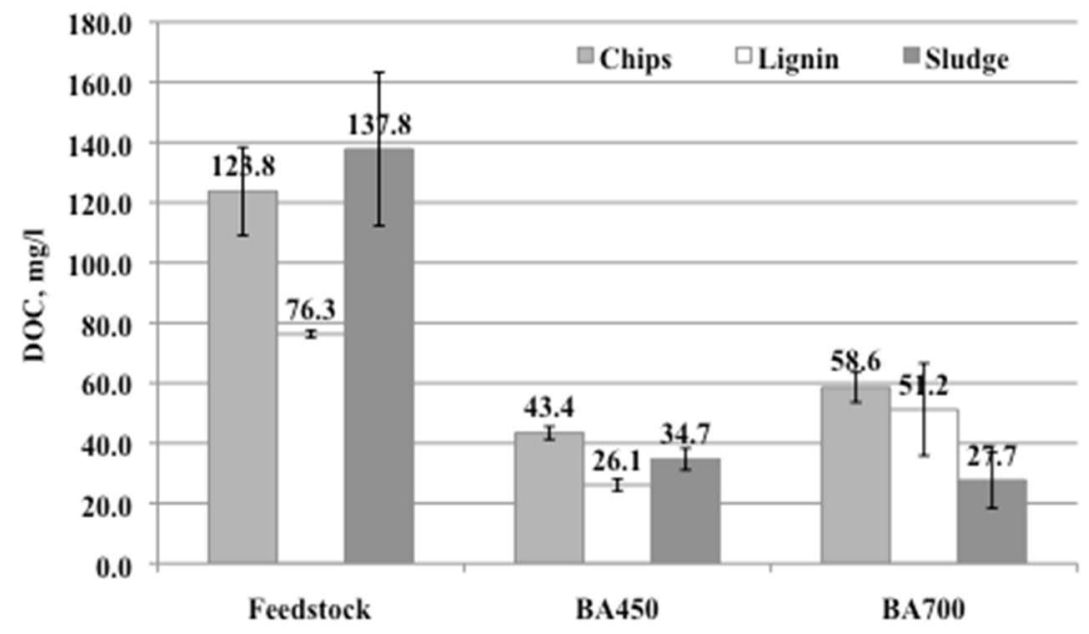

Figure 11. Dissolved organic carbon (DOC) of three types of feedstock (chips, lignin and sludge) and biochar produced at two temperatures $\left(450^{\circ} \mathrm{C}\right.$ and $\left.700^{\circ} \mathrm{C}\right)$. Error bars denote $\mathrm{SE}(\mathrm{n}=3)$

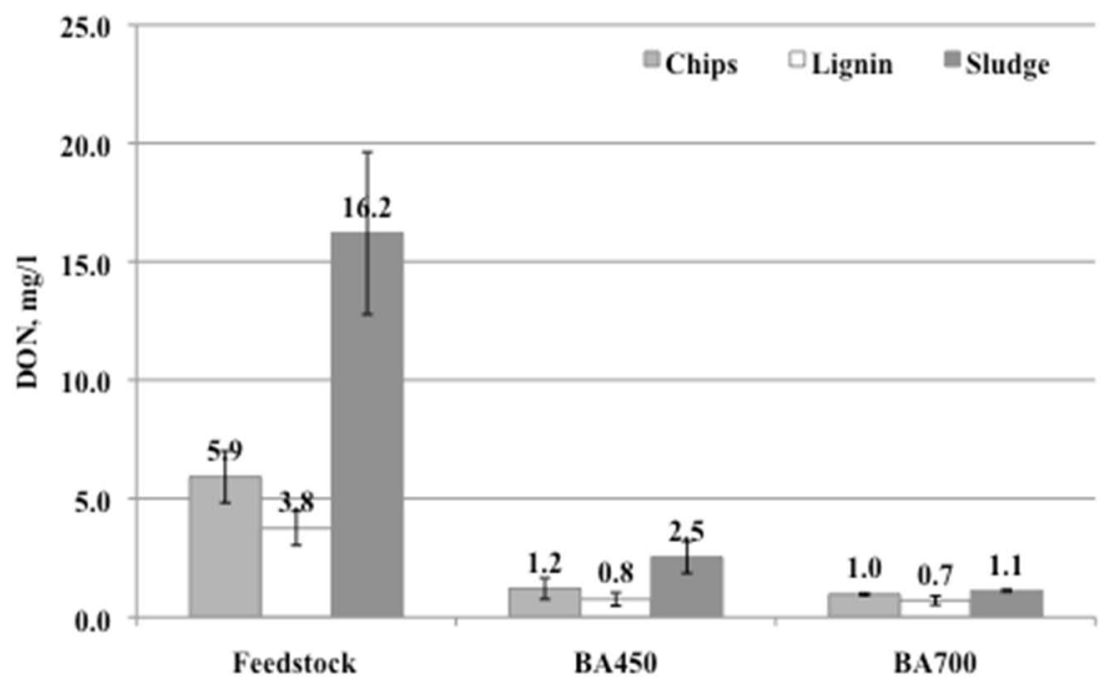

Figure 12. Dissolved organic nitrogen (DON) of three types of feedstock (chips, lignin and sludge) and biochar produced at two temperatures $\left(450^{\circ} \mathrm{C}\right.$ and $\left.700^{\circ} \mathrm{C}\right)$. Error bars denote $\mathrm{SE}(\mathrm{n}=3)$

The amounts of DOC and DON were lower in biochars than in their feedstocks (Fig 11 and 12), while DOC levels were higher and DON levels lower in biochars pyrolysed at $700^{\circ} \mathrm{C}$, compared to $450^{\circ} \mathrm{C}$ biochars. Sludge and sludge-derived biochars contained more DON than lignin or chip feedstock, or lignin and chip biochars. For DOC, the trend was similar except for the case of $700^{\circ} \mathrm{C}$ pyrolysis, when sludge biochar contained the least amount of soluble carbon. These results demonstrate that during the pyrolysis, the chemical structure of feedstock changes. Carbon and nitrogen become more recalcitrant, while some carbon and nitrogen are also volatilized from feedstock during the pyrolysis. The amounts of DOC and DON in the examined biochars are relatively small. According to the study of Jones et al. (2012), the use of biochar in agricultural fields did not affect soil DOC or DON pools. But it should be noted that potential leaching of metals, polycyclic aromatic hydrocarbons (PAHs) or other harmful substances from these biochars was not studied there. Some information about the toxicity of biochar leachates can be found in the study of Bernardo et al.(2014), who concluded that leachates from chars (mixture of plastic and pine waste) were not ecotoxic. On the other hand, Buss and Mašek (2014) have found that some re-condensed volatile organic compounds (VOCs) in biochar are mobile and phytotoxic. 
3 Fourier transform infrared spectroscopy was used in this study to describe the development and alterations in functional group chemistry of the studied types of biochar produced at two different temperatures. Chemical changes, depending on the temperature, were considerable. As shown in Fig 13 , sample spectra at $700^{\circ} \mathrm{C}$ appear to be very close to those of pure carbon, except for sludge. There is a very small IR response left in hydroxyl, hydrocarbon and fingerprint regions (regions 1 to 4 ), as well as trace responses in lignin and sludge samples at carbon hydrate backbone (region 5), while some traces are visible in all samples at aromatic out of plane absorbance (regions 6 to 8). The variation between samples at $700^{\circ} \mathrm{C}$ is residual carbon hydrate backbone (region 5) response. A response is strong in $\mathrm{S} 700$ sample, especially, when the sample process temperature is considered. There is a trace left in L700 and none of it is found in C700 sample.

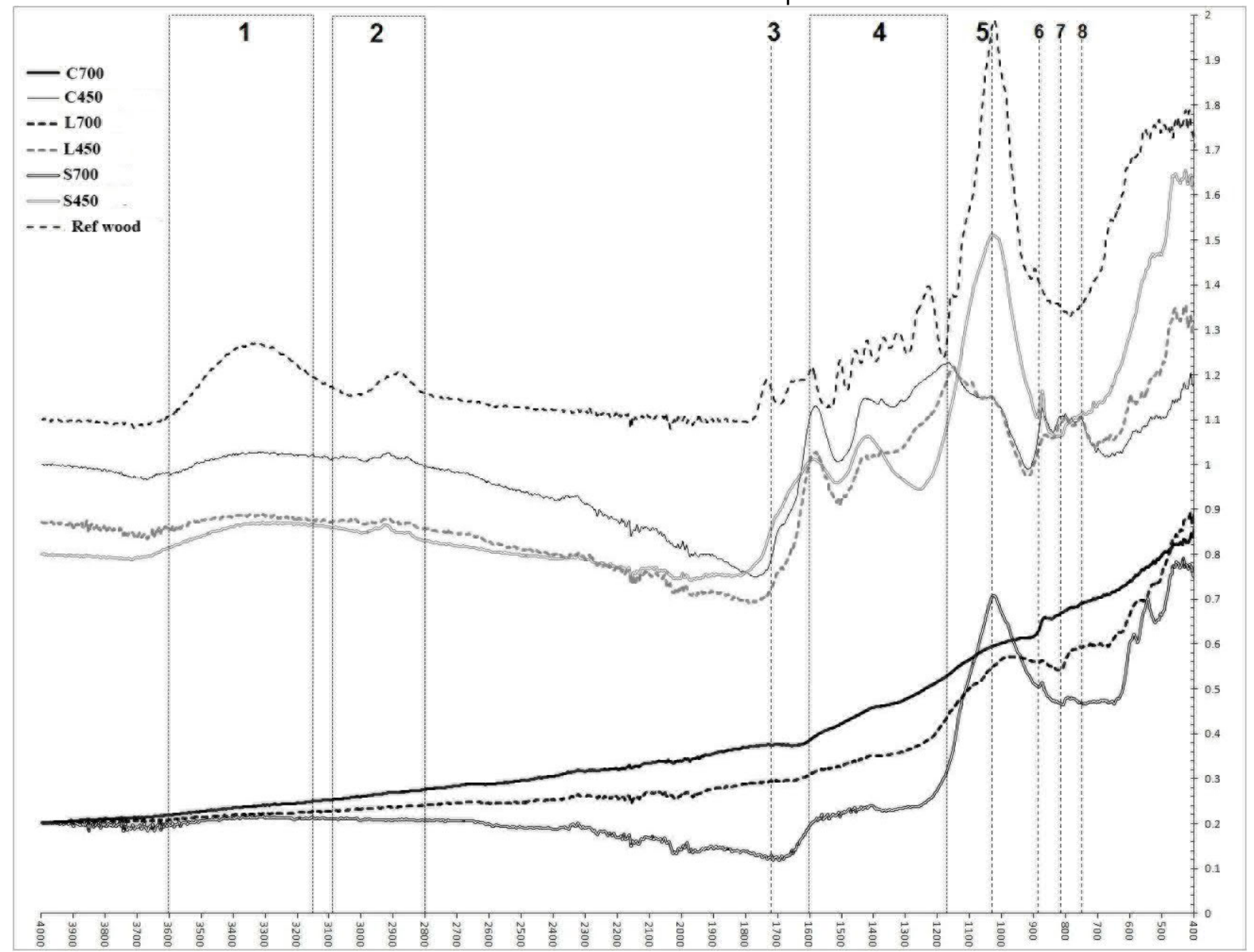

Figure 13. Fourier transform infrared (FTIR) spectra for three types of feedstock (chips, lignin and sludge) and biochar, produced at two temperatures $\left(450^{\circ} \mathrm{C}\right.$ and $\left.700^{\circ} \mathrm{C}\right): 1-$ hydrogen bonded $\mathrm{O}-\mathrm{H}$ stretch (WL 3150-3600), 2 - hydrocarbons (WL2800-3090), 3 - C=0 stretch (WL 1720), 4 - C=C, $\mathrm{C}=\mathrm{O}, \mathrm{C}-\mathrm{H}$ fingerprint region (WL 1150-1600), 5 - C-O (cellulose, hemicelluloses, metoxy-lignin) (WL 1030), 6 - aromatic C-H out of plane, cellulose nonsymmetric out-of-plane ring (WL 885), 7 aromatic C-H out of plane (WL 815), 8 - aromatic C-H out of plane (WL 750), WL - wavelength

20

21

22

23

Compared to $700^{\circ} \mathrm{C}$, much more diverse chemical structures are preserved in $450^{\circ} \mathrm{C}$ samples. As shown in Fig 13, the samples processed at $450^{\circ} \mathrm{C}$, demonstrate a considerable decrease in hydroxyl groups (region 1), but there are still some of them left. The $\mathrm{C}-\mathrm{H}$ vibrations (region 2) indicate the 
1 presence of hydrocarbon. There is a significant variation in the fingerprint region that can be 2 accounted for by the differences in raw materials or the variation in temperature or residence time 3 of samples. Zielinska et al. (2015) point out that due to the admixtures of minerals in sewage sludge 4 samples, IR bands overlap the bands of oxygen functional groups. There are traces of carbonyls 5 (region 3) in all samples, whereas L450 and C450 samples strongly resemble each other, with the 6 exception of the fingerprint region. S450, similar to S700, is rather different in the fingerprint region 7 (region 4), with a strong signal in region 5 and very little response in aromatic out of plane vibrations 8 (regions 6 to 8). The response in region 6 should be attributed to carbohydrate based on a strong 9 signal in region 5 in $\$ 450$ sample.

10 C700 compared to C450 is almost pure carbon. The IR response is almost completely missing, and

11 only its traces are left. The strongest response can be observed in region 6 . L700 is almost pure 12 carbon, with some traces of hydrocarbon or aromatic groups present. There is a very broad peak in 13 S700 between regions 5 and 6, and it is markedly different from S450, which still has some original carbohydrate. The feedstock of sludge appears to be relatively pure carbohydrate (cellulose). S450 and S700 are surprisingly similar. A major change is disappearing of hydroxyl and hydrocarbon signals (regions 1 and 2) at $700^{\circ} \mathrm{C}$ and the reduction of response in the fingerprint region. The $\mathrm{S} 700$ signal in region 5 is surprisingly strong, indicating the presence of carbohydrate structures, which have undergone dehydration reactions (more so in S700 than in S450). Almost completely missing indication of aromatic structures (in regions 6 to 8) (Fig 13) is also important.

In regard to the biofiltration systems, biochar produced at $450^{\circ} \mathrm{C}$, rather than that obtained at $700^{\circ} \mathrm{C}$ with diverse surface chemical structures, can be used for enhancing the adsorption of gaseous pollutants. This could be possible if the featuring biochar functionality would be designed, taking into account biofiltration conditions, pollutants to be removed from the stream and design of a biofilter. Aromatic functional groups, denoted by bands at $\sim 1600 \mathrm{~cm}^{-1}$, are found in all biochar samples produced at $450^{\circ} \mathrm{C}$ and can indicate high stability, which is the criterion used in the biofiltration method. Carboxyl structures observed to be stretching (at $\sim 1460 \mathrm{~cm}^{-1}$ ) along biochar samples produced at $450^{\circ} \mathrm{C}$ are known to increase biochar ability to retain nutrients (Glaser et al. 2001). In biofiltration, this may favour the microorganism attachment and development.

As concerns biofiltration phenomena, including biodegradation processes, as well as adsorption of contaminants on the surface of biochar, oxygen content was found to have an impact on them. As described by Pignatello et al. (2015), both general and specific effects of surface polar functional groups on adsorption mean that both polar and non-polar contaminants have an influence on the decrease in adsorption with increasing bulk oxygen content.

\subsection{SEM results}

The morphological structure of biochar, mainly presented in different types, size and shape of pores, as well as its physical-chemical properties, are highly variable and depend not only on the thermal treatment, but also on the chemical composition of biochar feedstock. In the lignocellulosic type of feedstock, it is mainly affected by the ratio of cellulose, hemicellulose and lignin (Baltrènas et al 2015). 


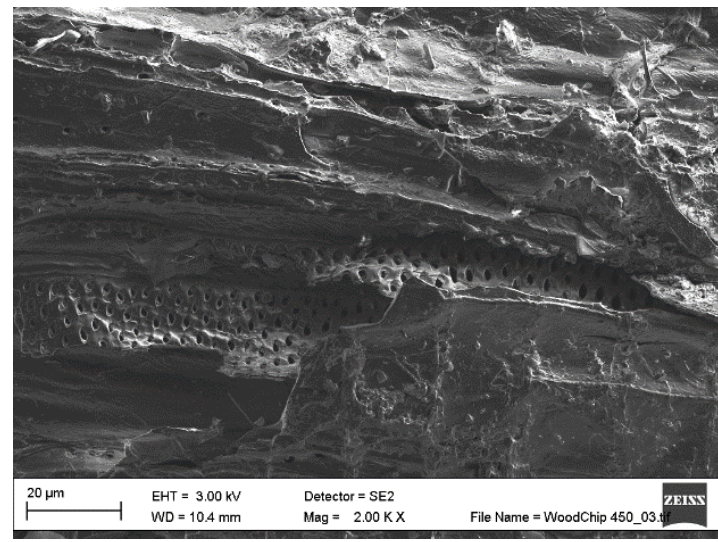

a)

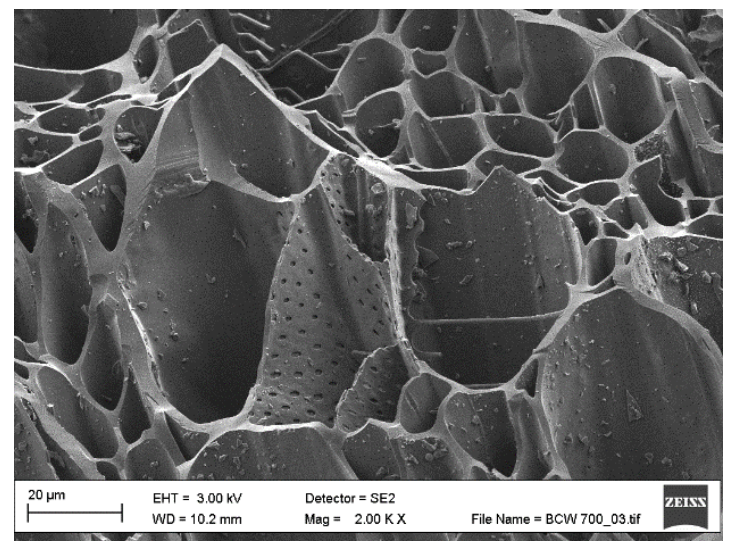

b)

\section{Figure 14. SEM images of biochar produced from woodchips (C): a) at 450॰ , magnification 2000}

times; b) at $700^{\circ} \mathrm{C}$, magnification 2000 times

As shown in Fig 14, a cellular structure was preserved in both C450 and C700 samples, but more defects were noticed in C450 rather than C700. C700 demonstrated the well-preserved cellular structure. Chips contained the particles representing a woody structure (Fig 14 a), which as magnified in Fig $14 \mathrm{~b}$, resembled the structure of hardwood. This is clearer when we observe fibers, which are typically arranged less perfectly than the fibers of softwoods and are interspersed with both shorter, thinner walled parenchyma cells and considerably larger diameter pores, or vessels. This structure provides better attachment for microorganisms and even the retention of macromolecules of contaminants, when it serves as a medium in a biofiltration system.

The SEM results of studying biochar obtained from lignin and sludge show that the structure of this biochar type depicts neither cellular nor fibrous structure. This was expected because of the fact that both lignin and sludge underwent mechanical treatment (as woodchips) and chemical treatment. Therefore, the lignocellulosic structures in sludge and lignin were affected by the type of treatment.

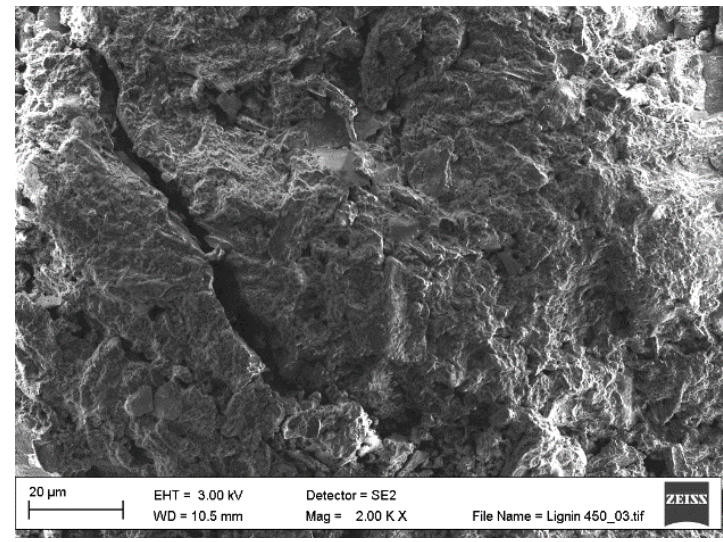

a)

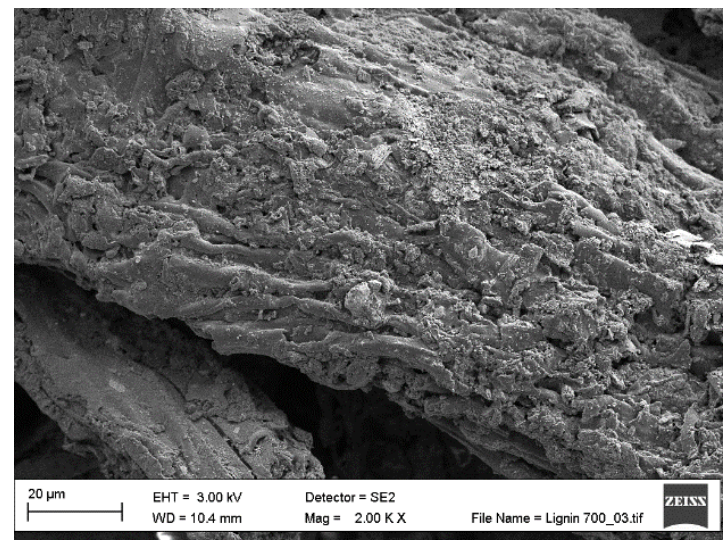

b)

17 Figure 15. SEM images of biochar produced from lignin (L): a) at 450 ${ }^{\circ} \mathrm{C}$, magnification 2000 times;

18

19

20

21

22

23 b) at $700^{\circ} \mathrm{C}$, magnification 2000 times

As shown in Fig $15 \mathrm{a}, \mathrm{b}$, neither cellular nor fibrous structure is present in L450, however, smaller particles are found in L700, but not in L450. 


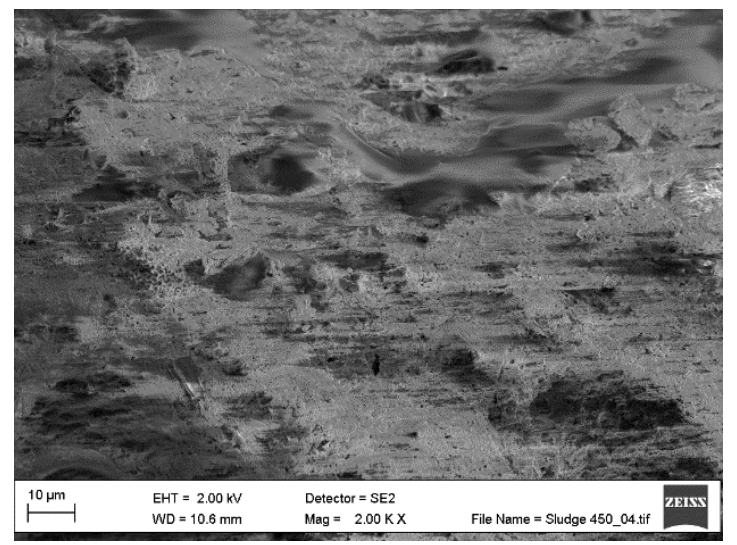

a)

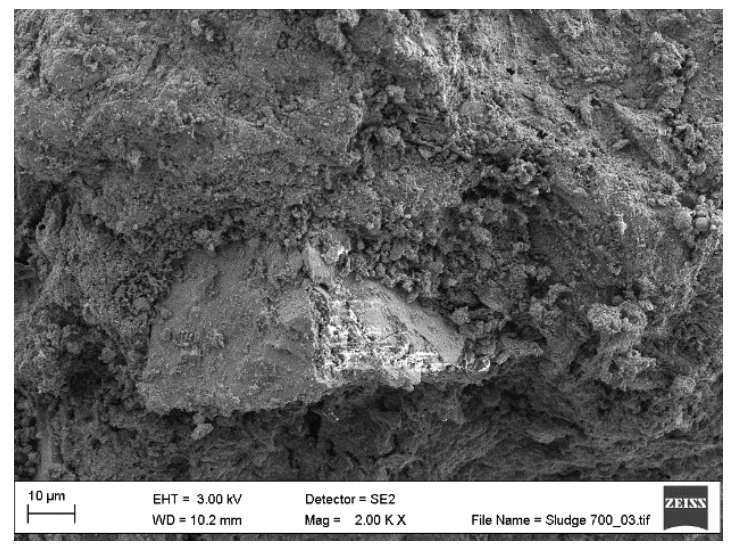

b)

Figure 16. SEM images of biochar produced from sludge (S): a) at 450C, magnification 2000 times;

b) at $700^{\circ} \mathrm{C}$, magnification 2000 times

As shown in Fig 16a,b, S450 presents homogenous mass, which is difficult to observe due to the lack of high resolution as the result of sludge charging. In S700, some crystal-like or chip-like features can be detected.

\subsection{Elemental ratios}

Once biochar is produced and introduced into the soil, or placed as a medium in the filtration systems or in some other way exposed to the surrounding environment, one of the first modifications of their organic molecular structure to occur is functionalization of the surface with O-containing functional groups (Kleber et al. 2016). The level of functionalization is highly dependent on the starting functional properties of biochar. We applied elemental ratios as the bulk analysis approach to characterize the examined types of biochar. Three types of ratios, in particular, $\mathrm{O} / \mathrm{C}, \mathrm{H} / \mathrm{C}$ and $(\mathrm{O}+\mathrm{N}) / \mathrm{C}$, were calculated to attribute biochar hydrophilicity, aromaticity and polarity level (Zielinska et al. 2015).

Ahmad et al. (2012) explained that the decrease in the value of the $\mathrm{O} / \mathrm{C}$ ratio with the increasing temperature resulted from the dehydration reaction and corresponded to the less hydrophilic biochar surface. However, in the present study, this trend could be observed for lignin and sludge biochars, but not for woodchip biochar. For the latter, the $\mathrm{O} / \mathrm{C}$ increased with the increase in the pyrolysis temperature. Moreover, woodchips biochar had the highest $\mathrm{O} / \mathrm{C}$ ratio compared to that of other considered types of biochar (Fig 17 a). Charring (especially, at high $\left(700^{\circ} \mathrm{C}\right)$ temperature) did not affect the O/C (i.e. hydrophilicity) of chips as much as it affected sludge and lignin. Since the decrease in the $\mathrm{O} / \mathrm{C}$ ratio is related to lower hydrophilicity of the biochar surface, it can be stated that charring preserves hydrophilicity of woodchips biochar, but reduces it in sludge and lignin types of biochar. The hydrophilicity decreases (hydrophobicity increases) due to a substantial loss of oxygen, which is also the effect of the removal of acidic functional groups. It suggests that woodchip biochar should lose a smaller amount of oxygen at a higher charring temperature than at a lower temperature. 


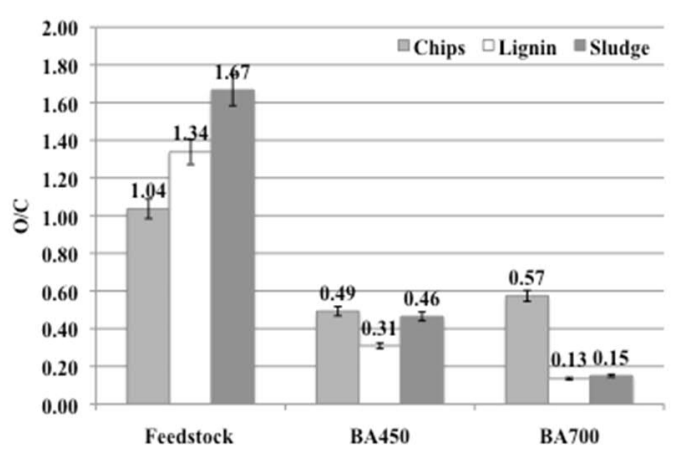

a)

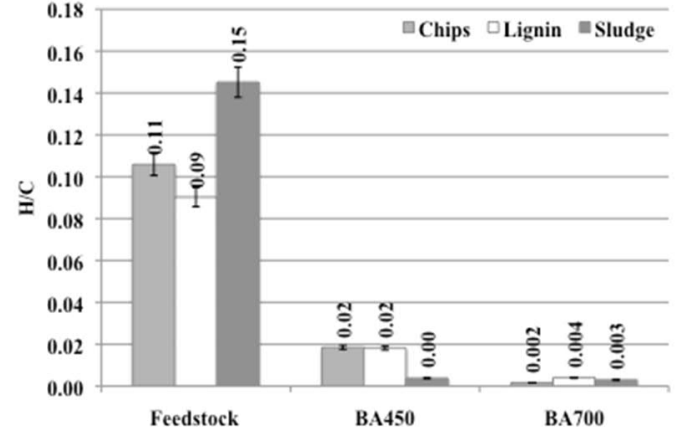

b)

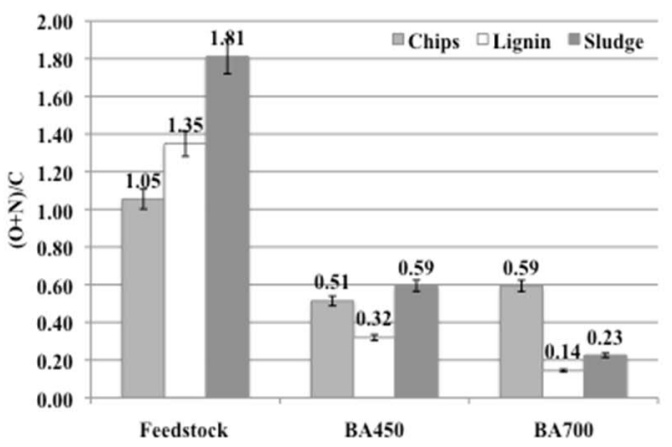

C)

Figure 17. Elemental ratios: a) O/ C; b) H/C; c) $(\mathrm{O}+\mathrm{N}) / \mathrm{C}$, characterizing biochar produced at $450^{\circ} \mathrm{C}$ and $700^{\circ} \mathrm{C}$ from lignin, sludge and woodchips

The $\mathrm{H} / \mathrm{Cratio}$ is among the parameters helping to identify the biochar carbonization level. Ahmad et al. (2012) have found that the $\mathrm{H} / \mathrm{C}$ ratio decreases at a higher carbonization level. In this study, the $\mathrm{H} / \mathrm{C}$ ratio decreased for the types of biochar produced at higher temperatures $\left(700^{\circ} \mathrm{C}\right)$. Biochar produced at higher temperatures is more degasified, loses hydrogen, is highly thermally modified and demonstrates high content of unsaturated structures. This favors higher aromaticity and a higher proportion of carbon and, therefore, results in the lower $\mathrm{H} / \mathrm{C}$ ratio. Among the studied types of biochar, the lowest $\mathrm{H} / \mathrm{C}$ values were obtained for sludge biochar at both temperatures of production compared to those for lignocellulosic biochar (i.e. lignin and woodchips). This difference is explained by different amounts of the primary organic material. The higher the content of organic material, the higher the $\mathrm{H} / \mathrm{C}$ value.

Zielinska et al. (2016) suggested that the $(\mathrm{O}+\mathrm{N}) / \mathrm{C}$ value should be used to describe the polarity of biochar and found that higher values characterize biochar containing polar functional groups potentially interacting with water. With the increase in temperature, the $(\mathrm{O}+\mathrm{N}) / \mathrm{C}$ value, and thus the amount of polar functional groups (or polarity), should decrease. However, this was true for lignin and sludge biochars, but not for woodchips. In the case of woodchip biochar, the opposite trend could be observed. In particular, the $(\mathrm{O}+\mathrm{N}) / \mathrm{C}$ value increased with the increase in temperature.

\subsection{PAH and trace elements}

The total PAH content of three biochar products ranged from $0.250 \mathrm{mg} / \mathrm{kg}$ DW (S700) to 9800 (L450) $\mathrm{mg} / \mathrm{kg}$, which is shown in Table 1 . The concentrations were dependent on the biochar source material and the pyrolysis production temperature. The majority of the 16 EPA PAH consisted of low molecule compounds. Indeed, the total contributions of naphthalene, fluorene and phenantrene were $92-95 \%, 89-92 \%$, and $65-85 \%$ for woodchip, lignin, and sludge chars at 450 and $700^{\circ}$, respectively with naphthalene being the dominant $\mathrm{PAH}$ compound in every biochar type. Interestingly 
1 four ring pyrene was also present in small quantities in all the samples excluding S700. The

2 concentrations of other high molecule PAHs (Table 1; Benzo[a]anthracene 3 Benzo[ghi]perylene) were ranging from negligible (below the detection limits) up to only 0.3 $4 \mathrm{mg} / \mathrm{kg}$ DW with a temperature-independent random pattern among the three types of feedstock. The total PAH concentrations decreased by a factor of 10 as the production temperature increased. Sludge biochar was different from other two types with regard to its three times lower total PAH concentrations., as well as the presence of four and five ring PAHs around the production temperature of $450^{\circ} \mathrm{C}$

Table 1. Concentrations of the 16 EPA PAHs $(\mathrm{mg} / \mathrm{kg}$ DW) (N.D. not detected, LOQ limit of quantification. $\mathrm{LOQ}=0.010 \mathrm{mg} / \mathrm{kg} \mathrm{DW}$ ) in biochar produced from three types of feedstock at two principal temperatures ( 450 and $700^{\circ} \mathrm{C}$ )

\begin{tabular}{|c|c|c|c|c|c|c|c|}
\hline & C450 & C700 & L450 & L700 & S450 & S700 & Blank \\
\hline Naphthalene & 6.62 & 0.682 & 5.86 & 0.668 & 1.60 & 0.0720 & $<\mathrm{LOQ}$ \\
\hline Acenaphthylene & 0.02 & $<\mathrm{LOQ}$ & N.D. & 0.0190 & N.D. & N.D. & N.D. \\
\hline Acenaphthene & N.D. & N.D. & N.D. & N.D. & N.D. & N.D. & N.D. \\
\hline Fluorene & 0.560 & 0.0970 & 0.403 & 0.0680 & 0.0970 & 0.0670 & $<\mathrm{LOQ}$ \\
\hline Phenanthrene & 1.57 & 0.0970 & 2.59 & 0.204 & 0.408 & 0.0690 & N.D. \\
\hline Anthracene & 0.147 & N.D. & 0.250 & 0.0170 & 0.0460 & $<\mathrm{LOQ}$ & N.D. \\
\hline Fluoranthene & 0.109 & 0.0150 & 0.105 & 0.0210 & 0.0830 & $<\mathrm{LOQ}$ & N.D. \\
\hline Pyrene & 0.151 & 0.0190 & 0.139 & 0.0190 & 0.112 & $<\mathrm{LOQ}$ & $<\mathrm{LOQ}$ \\
\hline Benzo[a]anthracene & 0.100 & N.D. & 0.160 & N.D. & 0.276 & N.D. & N.D. \\
\hline Chrysene & 0.0920 & N.D. & 0.197 & N.D. & 0.291 & N.D. & N.D. \\
\hline Benzo[b]fluoranthene & 0.0440 & 0.0110 & 0.0440 & N.D. & N.D. & 0.0260 & N.D. \\
\hline Benzo[k]fluoranthene & N.D. & N.D. & N.D. & N.D. & N.D. & N.D. & N.D. \\
\hline Benzo[a]pyrene & N.D. & N.D. & 0.0610 & N.D. & 0.185 & 0.0120 & N.D. \\
\hline Indeno[1,2,3-cd]pyrene & $<\mathrm{LOQ}$ & $<\mathrm{LOQ}$ & $<\mathrm{LOQ}$ & N.D. & N.D. & N.D. & 0.0390 \\
\hline Dibenzo[a,h]anthracene & $<\mathrm{LOQ}$ & N.D. & N.D. & N.D. & N.D. & N.D. & N.D. \\
\hline Benzo[ghi]perylene & N.D. & $<\mathrm{LOQ}$ & $<\mathrm{LOQ}$ & N.D. & 0.145 & N.D. & N.D. \\
\hline$\Sigma 16$ EPA PAHs & 9.42 & 0.919 & 9.81 & 1.02 & 3.24 & 0.246 & 0.0390 \\
\hline
\end{tabular}

13

14

15

16

17

18

19

20

21

22

23

24

25

26

27
In general, the results obtained in this study are in good agreement with those of other studies in terms of the specific PAH fingerprint (Hilbert et al. 2012), dominance of low molecule PAHs (Freddo et al 2012, Hale et al. 2012, De la Rose 2016), pyrolysis temperature relationship (Hale et al. 2012, Freddo et al. 2012), low sludge biochar PAH concentrations (Zielińska and Oleszczuk 2015), the total PAH concentrations measured (De la Rose et al. 2016, Hale et al. 2012, Mayer et al. 2016), and the analytic method application (Hilbert et al. 2012). According to Hilber et al. (2012), the observed naphthalane - phenanthrene fingerprint is specific and, in this case, similar to that of gasoline, but completely different for feedstock used for biochar, such as green waste. De la Rosa (2016) hypothesized that low-molecular-weight PAHs, and, specifically, naphthalane, are dominant at low pyrolysis temperatures $\left(\leq 500^{\circ} \mathrm{C}\right)$. Hale et al (2012) likewise suggest that most of the low molecular weight PAHs in biochars, especially, naphthalene and phenanthrene, were, probably, not present originally in the feedstock material, but were rather produced during pyrolysis. Our results support indirectly also the contention that sewage sludges conversion to biochar significantly reduced the content of PAHs (Zielinska and Oleszczuk 2015). 
With respect to the pyrolysis temperature, the higher pyrolysis temperature resulted in the lowest total PAH concentrations. Hale et al. (2012) concluded that with respect to the pyrolysis temperature, the higher pyrolysis temperature resulted in the lowest total PAH concentrations. The same was true of the three types of biochar used in this study. However, the opposite pattern, indicating that only rarely the results from PAH-related biochar studies are clear or consistent, is also reported (Zielinska and Oleszczuk 2016).

7 In regard to the EBC limit values for PAH in biochar (12 mg/ $\mathrm{kg}$ DW for basic grade biochar), the limit 8 values were not exceeded for the studied types of biochar. Biochar with higher ash content produced 9 at a higher temperature $\left(700^{\circ} \mathrm{C}\right)$ was characterized by lower concentration of PAH. The present study 10 has shown that $\mathrm{PAH}$ concentration is roughly 10 times lower in biochar produced at $700^{\circ} \mathrm{C}$ than in 11 biochar produced at $450^{\circ} \mathrm{C}$.

12 The concentrations of trace elements $(\mathrm{Cd}, \mathrm{Cr}, \mathrm{Cu}, \mathrm{Ni}, \mathrm{Pb}, \mathrm{Zn})$ in three types of feedstock (chips, lignin and sludge), as well as biochar produced at two temperatures $\left(450^{\circ} \mathrm{C}\right.$ and $\left.700^{\circ} \mathrm{C}\right)$, are extensively discussed in the paper of Mancinelli et al. (2016), but some key conclusions aiming to define the type of material and its treatment level, at which the concentration of trace elements is the lowest are presented here. In the case of lignin, the lowest concentration of trace elements (except $\mathrm{Cd}$ ) was found in lignin biochar produced at $450^{\circ} \mathrm{C}$. For other types of feedstock, the trend was not so clear. The total concentration of trace elements in the studied types of feedstock and biochar, was decreasing in the following order: sludge >lignin >chips. The prevailing trace elements in sludge and its biochar were $\mathrm{Cr}$, $\mathrm{Cu}$ and $\mathrm{Zn}$ (exceeding the limit values given in the European Biochar Certificate (EBC 2012) by 3, 7 and 6 times, respectively), for lignin - $\mathrm{Cr}$ and $\mathrm{Cu}$ (exceeding the limit values given in the European Biochar Certificate by 2 and 5 times, respectively) and for woodchips - Zn (exceeding the limit value given in the European Biochar Certificate by 3 times).

\subsection{A systematic comparison of biochar used in biofiltration systems}

Table 2 provides a systematic comparison of biochar parameters to facilitate the identification of biochar closely matching the criteria of the biofiltration medium (Fig 1).

Table 2. A systematic overview of the parameters and their extent in biochar produced from three types of feedstock at two principal temperatures ( 450 and $700^{\circ}$ C): " 3 " indicates a higher extent and " 1 " refers to a lower extent of a particular parameter in the particular type of biochar. Shaded numbers denote the best value of a particular parameter

\begin{tabular}{|l|c|c|c|c|c|c|}
\hline \multicolumn{1}{|c|}{ Parameter } & S450 & CA50 & L450 & S700 & C700 & L700 \\
\hline Ash content & 3 & 1 & 2 & 3 & 1 & 2 \\
\hline Total carbon content & 1 & 3 & 2 & 1 & 3 & 2 \\
\hline Bulk density & 3 & 1 & 2 & 2 & 1 & 2 \\
\hline Water holding capacity & 1 & 3 & 2 & 1 & 3 & 2 \\
\hline pH & 2 & 3 & 1 & 3 & 2 & 1 \\
\hline Electrical conductivity & 3 & 1 & 2 & 3 & 1 & 2 \\
\hline Dissolved organic carbon & 2 & 3 & 1 & 1 & 3 & 2 \\
\hline Dissolved organic nitrogen & 3 & 2 & 1 & 3 & 2 & 1 \\
\hline Aromatic structures & 1 & 3 & 3 & 1 & 3 & 3 \\
\hline Pore development & 1 & 3 & 2 & 1 & 3 & 2 \\
\hline Hydrophilicity level, O/C & 2 & 3 & 1 & 2 & 3 & 1 \\
\hline Aromaticity level, H/C & 1 & 2 & 2 & 2 & 1 & 3 \\
\hline Polarity level, (O+N)/C & 3 & 2 & 1 & 2 & 3 & 1 \\
\hline Trace elements & 3 & 1 & 2 & 3 & 1 & 2 \\
\hline PAHs & 1 & 2 & 3 & 1 & 2 & 3 \\
\hline
\end{tabular}

33

34

35
Table 2 demonstrates the main tendency. Among the studied types of biochar exhibiting dissimilar properties, the wood-chips-derived biochar had the characteristics favourable for a biofiltration 
system. Irrespective of the production temperature, biochar obtained from woodchips had lower ash content and bulk density, as well as low electrical conductivity and a lower amount of trace elements. On the other hand, it was characterized by higher total carbon content, a higher water holding capacity and could develop more aromatic structures and the pore structure more beneficial for microorganisms. The concentration of PAH was also not high. This means that biochar obtained from the lignocellulosic type feedstock has more benefits for being used as a biofiltration medium than biochar obtained from the feedstock with higher lignin content or waste with high ash content (i.e. sludge).

\subsection{Production of biochar from waste biomass in the developing countries}

Biochar belongs to the organic-origin materials, the demand for which has been increasing in many economic fields. This growth is mainly associated with biowaste as potential feedstock for biochar production, with its further diversified use. The largest share of biomass and biowaste in the world is expected to be found in the developing countries. They have a potential to produce biomass at lower cost than that in the industrialized countries due to better climate and lower labour costs, which may be considered an advantage. Crops residue itself makes about 3 billion tonnes per year in 25 developing countries (Ullah et al. 2015). Although most of these residues are intended for the secondgeneration biofuels, biowaste as a carbonaceous material could have a share in the production of biochar. Due to a wider and effective use in soil and for the potential climate change mitigation, biochar is more competitive now than activated used in the environmental engineering systems. The perspectives of biochar use for contaminant removal from the environmental media are expected to be in line due to the growth of the activated carbon market, which is expected to reach 2.4 million metric tons by 2020, with a driving force to be legislation and strict enforcement of the environmental regulations (A global strategic business report 2016).

\section{Conclusions and recommendations for further studies}

1. Biochar as an option for resource management or waste management alternative has been widely studied for its role in soil environment, but found an application for the environmental protection technologies, such as biofiltration. This was highly favoured for some reasons, including the fact that many of the environmental protection technologies employ natural phenomena (because biofiltration is based on contaminant biodegradation by microorganisms living on the substrate). The environmental protection technologies shift to a more sustainable level with the focus on using sustainably obtained materials, whose demand and market are being extended by more rigorous environmental legislation.

2. A lignocellulosic type of biochar was found to be more competitive for use as a biofiltration medium than the types of biochar with high ash or lignin content. Irrespective of the production temperature, biochar obtained from woodchips has lower ash content and bulk density, as well as lower electrical conductivity and lower content of trace elements. On the other hand, it usually has higher total carbon content and a higher water holding capacity. It can also develop more aromatic structures and the pore structure, which is more beneficial for microorganisms, and it has a relatively low concentration of potentially toxic elements.

3. Biochar production temperature $\left(450\right.$ and $\left.700^{\circ} \mathrm{C}\right)$ does not affect its characteristics, since the characteristics are different because of the inherent properties of feedstock. Therefore, lower temperature $\left(450^{\circ} \mathrm{C}\right)$ biochar obtained from woodchips can be used for biofiltration similar to biochar produced at $700^{\circ} \mathrm{C}$.

4. Further studies of the biochar use for biofiltration could focus on the classification of biochar types used for biofiltration of particular contaminants from the air stream. Besides, the more extensive testing of biochar in pilot-scale biofiltration systems is advisable.

\section{Acknowledgement}


The authors thank Assoc. Prof. Dr Dainius Paliulis, Assoc. Prof. Dr Eglè Marčiulaitienė and Emmi Vähä for their assistance in sample preparation and analysis.

\section{References}

A global strategic business report, 2016. MCP-1825: activated carbon, assessed via www.strategyR.com.

Ahmad, M., Lee, S. S., Dou, X., Mohan, D., Sung, J.-K., Yang, J. E., et al., 2012. Effects of pyrolysis temperature on soybean stover- and peanut shell-derived biochar properties and TCE adsorption in water. Bioresource Technology 118, 536-544.

Aygun, A., Yenisoy-Karakas, S., Duman, I., 2003. Production of granular activated carbon from fruit stones and nutshells and evalution of their physical, chemical and adsorption properties. Microporous and Mesoporous Materials 66, 189-195.

Baltreinaitė, E., Baltrenas, P., Lietuvninkas, A., 2016. The Sustainable Role of the Tree in Environmental Protection Technologies. Springer. Monograph. 300 p.

Baltrènas, P., Baltrènaitè, E., Kleiza, J., Svedienė, J., 2016. A biochar-based medium in the biofiltration system: removal efficiency, microorganism propagation and the medium penetration modeling. Journal of Air and Waste Management Association 66(7), 673-686.

Baltrènas, P., Baltrėnaitè, E., Spudulis, E., 2015. Biochar from pine and birch morphology and pore structure change by treatment in biofilter. Water, Air and Soil Pollution 226(69), 1-14.

Bernardo, M., Mendes, S., Lapa, N., Goncalves, M., Mendes, B., Pinto, F., Lopes, H., 2014. Leaching behavior and ecotoxicity evaluation of chars from the pyrolysis of forestry biomass and polymeric materials. Ecotoxicology and Environmental Safety 107, 9-15.

Brewer, C. E., Schmidt-Rohr, K., Satrio, J. A., Brown, R. C., 2009. Characterization of biochar from fast pyrolysis and gasification systems, Environmental Progress and Sustainable Energy 28, 386396.

Brown, R., del Campo, B., Boateng, A. A., Garcia-Perez, M., Mašek, O., 2015. Fundamentals of biochar products. In: Lehmann J, Joseph S (eds) Biochar for Environmental Management: science, technology and implementation, 39-61.

Buss, W., Mašek, O., 2014. Mobile organic compounds in biochar - A potential source of contamination - Phytotoxic effects on cress seed (Lepidium sativum) germination. Journal of Environmental Management 137, 111-119.

Chupka, E. I., Rykova, T. M., 1983. Electrical properties of lignin. Khimiya Prirodnykh Soedinenii 1, 82-85.

De la Rosa, J. M., Paneque, M., Hilber, I., Blum, F., Knicker, H. E., Bucheli, T. D., 2016. Assessment of polycyclic aromatic hydrocarbons in biochar and biochar-amended agricultural soil from Southern Spain. J Soil Sediments 16, 557-565.

Devinny, J. S., Deshusses, M. A., Webster, T. S., 1999. Biofiltration for air pollution control. CRC press LLC.

EBC, 2012. European Biochar Certificate - Guidelines for a Sustainable Production of Biochar. European Biochar Foundation (EBC), Arbaz, Switzerland. http://www.europeanbiochar.org/en/download. Version 6.2E of 04th February 2016, DOI:10.13140/ RG.2.1.4658.7043.

Enders, A., Hanley, K., Whitman, T., Joseph, S., Lehmann, J., 2012. Characterization of biochars to evaluate recalcitrance and agronomic performance. Bioresource Technology 114, 644-653

Freddo, A., Cai, C., Reid, B. J., 2012. Environmental contextualisation of potential toxic elements and polycyclic aromatic hydrocarbons in biochar. Environmental Pollution 171, 18-24.

Ghani, W. A., Mohd, A., da Silva, G., Bachmann, R. T., Taufiq-Yap, Y. H., Rashid, U., Al-Muhtaseb, A. H., 2013. Biochar production from waste rubber-wood-sawdust and its potential use in $C$ sequestration: Chemical and physical characterization. Industrial Crops and Products 44,1824. 
Glaser, B., Haumaier, L., Guggenberger, G., Zech, W., 2011. The 'terra preta' phenomenon: a model for sustainable agriculture in the humid tropics, Naturwissenschaften 88, 37-41.

Hale, S. E., Lehmann.J., Rutherford. D., Zimmerman, A. R., Bachmann, R. T., Shitumbanuma, V., O'Toole, A., Sundqvist, K. L., Arp, H. P. H., Cornelissen, G., 2012. Quantifying the total and bioavailable polycyclic aromatic hydrocarbons and dioxins in biochars. Environ Sci Technol 46, 28302838.

Havukainen, J., Zavarauskas, K., Denafas, G., Luoranen, M., Kahiluoto, H., Kuisma, M., Horttanainen, M., 2011. Potential of energy and nutrient recovery from biodegradable waste by co-treatment in Lithuania. Waste Management and Research, 1-9.

Hilber, I., Blum, F., Leifeld, J., Schmidt, H. P., Bucheli, T., 2012. Quantitative determination of PAHs in biochar: a prerequisite to ensure its quality and safe application.J Agric Food Chem 60, 30423050.

Hilber, I., Bastos, A., Loureiro, S., Soja, G., Marsz, A., Cornelissen, G., Bucheli, T., 2016. The different fases of biochar: contamination risk versus remediation tool. Journal of Environmental Engineering and Landscape Management. Submitted.

Jones, D. L., Willet, V. B., 2006. Experimental evaluation of methods to quantify dissolved organic nitrogen (DON) and dissolved organic carbon (DOC) in soil. Soil Biology and Biochemistry 38, 991-999.

Jones, D. L., Rousk, J., Edwards-Jones, G., DeLuca, T.H., Murphy, D. V., 2012. Biochar-mediated changes in soil quality and plant growth in a three-year field trial. Soil Biology \& Biochemistry 45, 113124.

Kaal, J., Cortizas, A. M., Reyes, O., Soliño, M., 2012. Molecular characterization of Ulex europaeus biochar obtained from laboratory heat treatment experiments - A pyrolysis-GC/ MS study. Journal of Analytical and Applied Pyrolysis 95, 205-212.

Keiluweit, M., Nico, P. S., Johnson, M. G., Kleber, M., 2010. Dynamic Molecular Structure of Plant Biomass-Derived Black Carbon (Biochar). Environmental Science and Technology 44, 12471253.

Kleber, M., Hockaday, W., Nico, P. S., 2016. Characteristics of biochar: macro-molecular properties. In: Lehmann, S., Joseph, S., (eds) Biochar for environmental management: science, technology and implementation. Second edition, Earthscan, Cornwall.

Kloss, S., Zehetner, F., Dellantonio, A., Hamid, R., Ottner, F., Liedtke, V., Schwanninger, M., Gerzabek, M.H., Soja, G., 2012. Characterization of slow pyrolysis biochars: effects of feedstocks and pyrolysis temperature on biochar properties. Journal of Environmental Quality 41, 990-1000.

Laird, D., Rogovska, N., 2015. Biochar effects on nutrient leaching. In: Lehmann, S., Joseph, S., (eds) Biochar for environmental management: science, technology and implementation. Second edition, Earthscan, Cornwall.

Lin, Y., Munroe, P., Joseph, S., Henderson, R., 2012. Migration of dissolved organic carbon in biochars and biochar-mineral complexes. Pesq. agropec. bras., Brasília, v.47, n.5, p.677-686

Mancinelli, E., Baltrènaitè, E., Baltrènas, P., Paliulis, D., Passerini, G., 2016. Trace metals in biochars from biodegradable by-products of industrial processes. Water, air and soil pollution 227 (6), $1-21$.

Mancinelli, E., Baltrėnaitė, E., Baltrėnas, P., Marčiulaitienė, E., Passerini, G., 2016. Dissolved organic carbon content and leachability of biomass waste biochar for trace metal $(\mathrm{Cd}, \mathrm{Cu}$ and $\mathrm{Pb})$ speciation modelling. Journal of Environmental Engineering and Landscape Management. Submitted.

Mayer, P., Hilber, I., Gouliarmou, V., Hale, S. E., Cornelissen, G., Bucheli, T. D., 2016. How to determine the environmental exposure of PAHs originating from biochar. Environ Sci Technol 50, 19411948. 
Mayer, S., Genesio, L., Ines, V., Schmidt, H.-P., Soja, G., Someus, E., Shackley, S., Verheijen, F., Glaser, B., 2016. Biochar standartization and legislation harmonization. Journal of Environmental Engineering and Landscape Management. Submitted.

Novak, J. M., Lima, I., Xing, B., Gaskin, J. W., Steiner, C., Das, K. C., Ahmedena, M., Rehrah, D., Watts, D. W., Busscher, W. J., Schomberg, H., 2009. Characterization of designer biochar produced at different temperatures and their effects on a loamy sand. Annals of Environmental Science 3, 195-206.

Pietikainen, J., Kiikkila, O., Fritze, H., 2000. Charcoal as a habitat for microbes and its effect on the microbial community of the underlying humus. Oikos 89, 231-242.

Pignatello, J.J., Uchimiya, M., Abiven, S., Schmidt, M.W.I., 2015. Evolution of biochar properties in soil. In: Biochar for Environmental Management - Science, Technology and Implementation. (eds Lehmann, J., Joseph, S.) pp Page. New York, Routledge.

Rostad, C. E., Rutherford, D. W., Wershaw, R. L., 2010. Effects of formation conditions on biochar on water extracts, GSA Denver Annual Meeting, Denver, CO.

Singh, B., Singh, B.P., Cowie, A. L., 2010. Characterization and evaluation of biochar for their application as a soil amendment, Soil Research 48, 516-525.

Spokas, K. A., Novak, J. M., Stewart, C. E., Cantrell, K. B., Uchimiya, M., DuSaire, M. G., Ro, K. S., 2011. Qualitative analysis of volatile organic compounds on biochar. Chemosphere 85, 869-882.

Tammeorg, P., Bastos, A., Jeffery, S., Rees, F., Juergen, K., Graber, E., Ventura, M., Kibblewhite, M., Amaro, A., Budai, A., Cordovil, C., Domene, X., Gardi, C., Gasco, G., Horak, J., Kammann, C., Kondrlova, E., Laird, D.,Loureiro S., Martins, M., 2016. Biochars in soils: towards the required level of scientific understanding. Journal of Environmental Engineering and Landscape Management. Submitted.

Ullah, K., Sharma, V. K., Dhingra, S., Braccio, G., Ahmad, M., Sofia, S., 2015. Assessing the lignocellulosic biomass resources potential in developing countries: A critical review. Renewable and Sustainable Energy Reviews 51, 682-698.

Vassilev, S. V., Baxter, D., Andersen, L. K., Vassileva, C. G., 2013. An overview of the composition and application of biomass ash.Part 1.Phase-mineral and chemical composition and classification. Fuel 105, 40-76.

Verheijen, F., Mankasingh, U., Penizek, V., Panzacchi, P., Glaser, B., Jeffery, S., Bastos, A., Tammeorg, P., Kern, J., Zavalloni, C., Zanchettin, G., Sakrabani, R., 2016. Representativeness of European biochar research: Part I field experiments. Journal of Environmental Engineering and Landscape Management. Submitted.

Villanueva, A., Delgado, L., Luo, Z., Eder, P., Catarino, A. S., Litten, Don., 2010. Study on the selection of waste streams for end-of-waste assessment (pp. 40-42). Luxembourg: Publications Office of the European Union. Final Report.

World Health Organization, 2016, The public health impact of chemicals: knows and unknowns. International Programme on Chemical Safety. 16 p.

Zielinska, A., Oleszczuk, P., Charmas, B., Skubiszewska-Zieba, J., Pasieczna-Patkowska, S., 2015. Effect of sewage sludge properties on the biochar characteristic. Journal of Analytical and Applied Pyrolysis 112, 201-213.

Zimmermann, A. R., Gao, B., Ahn, M.-Y. 2011. Positive and negative carbon mineralization priming effects among a variety of biochar-amended soils, Soil Biology nad Biochemistry, 43, 11691179.

Zhang, J., Liu, J., Liu, R., 2015. Effects of pyrolysis temperature and heating time on biochar obtained from the pyrolysis of straw and lignosulfonate. Bioresource Technology 176, 288-291.

Zielinska, A., Oleszczuk, P., 2015. The conversion of sewage sludge into biochar reduces polycyclic aromatic hydrocarbon content and ecotoxicity but increases trace metal content. Biomass and Bioenergy 75, 235-244. 
1 Zielinska, A., Oleszczuk, P., 2016. Effect of pyrolysis temperatures on freely dissolved polycyclic 2 aromatic hydrocarbon (PAH) concentrations in sewage sludge-derived biochars. 3 Chemosphere 153, 68-74. 